\title{
mTOR Modulates Methamphetamine-Induced Toxicity through Cell Clearing Systems
}

\author{
Gloria Lazzeri $\left(\mathbb{D},{ }^{1}\right.$ Francesca Biagioni $\left(\mathbb{D},{ }^{2}\right.$ Federica Fulceri $\left(\mathbb{D},{ }^{3}\right.$ Carla L. Busceti $\left(\mathbb{D},{ }^{2}\right.$ \\ Maria C. Scavuzzo $\left(\mathbb{D},{ }^{1}\right.$ Chiara Ippolito, ${ }^{3}$ Alessandra Salvetti $\left(\mathbb{D},{ }^{3}\right.$ Paola Lenzi $\left(\mathbb{D},{ }^{1}\right.$ \\ and Francesco Fornai $\mathbb{I D}^{1,2}$ \\ ${ }^{1}$ Department of Translational Research and New Technologies in Medicine and Surgery, Human Anatomy, University of Pisa, \\ Via Roma 55, Pisa 56126, Italy \\ ${ }^{2}$ I.R.C.C.S Neuromed, Via Atinense 18, Pozzilli 86077, Italy \\ ${ }^{3}$ Department of Clinical and Experimental Medicine, University of Pisa, Via Roma 55, Pisa 56126, Italy
}

Correspondence should be addressed to Francesco Fornai; francesco.fornai@med.unipi.it

Received 26 April 2018; Accepted 31 August 2018; Published 29 October 2018

Academic Editor: Brian Harvey

Copyright ( 2018 Gloria Lazzeri et al. This is an open access article distributed under the Creative Commons Attribution License, which permits unrestricted use, distribution, and reproduction in any medium, provided the original work is properly cited.

\begin{abstract}
Methamphetamine (METH) is abused worldwide, and it represents a threat for public health. METH exposure induces a variety of detrimental effects. In fact, METH produces a number of oxidative species, which lead to lipid peroxidation, protein misfolding, and nuclear damage. Cell clearing pathways such as ubiquitin-proteasome (UP) and autophagy (ATG) are involved in METH-induced oxidative damage. Although these pathways were traditionally considered to operate as separate metabolic systems, recent studies demonstrate their interconnection at the functional and biochemical level. Very recently, the convergence between UP and ATG was evidenced within a single organelle named autophagoproteasome (APP), which is suppressed by mTOR activation. In the present research study, the occurrence of APP during METH toxicity was analyzed. In fact, coimmunoprecipitation indicates a binding between LC3 and P20S particles, which also recruit p62 and alpha-synuclein. The amount of METH-induced toxicity correlates with APP levels. Specific markers for ATG and UP, such as LC3 and P20S in the cytosol, and within METH-induced vacuoles, were measured at different doses and time intervals following METH administration either alone or combined with mTOR modulators. Western blotting, coimmunoprecipitation, light microscopy, confocal microscopy, plain transmission electron microscopy, and immunogold staining were used to document the effects of mTOR modulation on METH toxicity and the merging of UP with ATG markers within APPs. METH-induced cell death is prevented by mTOR inhibition, while it is worsened by mTOR activation, which correlates with the amount of autophagoproteasomes. The present data, which apply to METH toxicity, are also relevant to provide a novel insight into cell clearing pathways to counteract several kinds of oxidative damage.
\end{abstract}

\section{Introduction}

Methamphetamine (METH) is a highly addictive and neurotoxic drug, which causes a variety of neuropsychiatric alterations mainly affecting the dopamine (DA) mesostriatal and mesolimbic systems in the brain $[1,2]$. Exposure to repeated doses of METH produces striatal DA depletion and loss of mesostriatal DA terminals [3-12].

In the cell body of the substantia nigra pars compacta $(\mathrm{SNpc}), \mathrm{METH}$ produces alterations in the cytoplasm which also occur in DA-PC12 cells and extend to the cytoplasm and nucleus of striatal GABA neurons $[6,13-16]$. These alterations configure as multilamellar whorl staining for ubiquitin, parkin, and alpha-synuclein $[6,15,17]$. Recent studies indicate that high METH doses may reduce the number of nigral cell bodies $[8,18]$. METH toxicity against DA cell bodies and axons relates to an increase of DA release and oxidative species [19]. In fact, METH alters the vesicular storage of DA [20-22], it inhibits physiological DA metabolism, which is naturally operated by MAO-A $[23,24]$, and it reverts and/or inhibits the activity of the plasma membrane DA transporter (DAT), thus leading to a loss of DATbinding sites $[1,25,26]$. All these effects contribute to rise of dramatically free DA levels within the cytosol of DA- 
containing cells. Since DA is no longer metabolized by MAOA, it undergoes self-oxidation and spontaneous conversion to DA quinones, which in turn generate highly reactive oxidative species $[27,28]$. In this way, a redox imbalance is generated by METH, which is detrimental for the integrity of both axon terminals and cell bodies where oxidized proteins, lipids, and nucleic acids are generated [29, 30]. A key molecular mechanism of protein oxidation consists in binding to cysteinyl residues to generate disulphuric bridges, which alter protein conformation $[28,31]$. In this way, misfolded proteins such as alpha-synuclein $[6,14]$, ubiquitin $[6,32]$, prion protein [33], and parkin [6,34] are generated. Again, METH inhibits complex II of the mitochondrial respiratory chain, which further elevates oxidative species and increases the number of altered mitochondria [35-39]. METH also oxidizes lipids to produce highly reactive by-products such as 4-hydroxynonenal $[34,40,41]$. All these oxidized substrates represent a target for cell clearing systems, which promote their removal. Thus, autophagy (ATG) and ubiquitinproteasome (UP) represent a powerful defense to counteract redox imbalance generated by such a drug of abuse, and they are both challenged by METH administration. In detail, UP activity is inhibited by METH $[13,15,16,34]$, while UP inhibitors produce subcellular alterations which overlap with those produced by METH $[6,14,42]$. In line with this, METH toxicity is enhanced by concomitant exposure to UP inhibitors $[15,43]$. ATG is quickly engaged during METH in PC12 cells $[22,44]$ and in vivo, in the SNpc and striatum $[6,15,45]$. Similarly to UP inhibitors, ATG blockers worsen METH toxicity [37]. Despite a massive engagement of ATG, which should sort neuroprotection, its activity is impaired by METH itself since the high amount of substrates (misfolded proteins and damaged mitochondria) engulfs this clearing system $[16,37,46]$. Therefore, despite being ATG overexpressed following METH $[22,44]$, it is not considered to be effective due to a lack of its progression $[37,46]$. Such a combined defect in cell clearing systems produced by METH paves the way to deleterious effects induced by oxidative species, which are abundantly produced by such a drug of abuse.

Recently, a cell clearing organelle, which possesses both ATG and UP components, was described. This organelle appears as a multilamellar vacuole, which carries both UP and ATG key antigens [47]. This organelle corresponds to the "autophagoproteasome" (APP) as being defined in the Glossary published in the consensus manuscript "Guidelines for the Use and Interpretation of Assays for Monitoring Autophagy (3rd Edition)" by Klionsky et al. [48]. In the recent manuscript, it was demonstrated that APP is strongly activated by mTOR inhibition [47]. In fact, when the mTOR inhibitor rapamycin is administered, roughly all UP-positive puncta detected by P20S immunostaining at confocal microscopy move towards LC3-positive vacuoles, thus producing a massive switch from cytosolic to compartmentalized proteasome [47]. Despite a strong involvement of UP and ATG per se during METH toxicity, no study so far investigated what happens to this merging organelle. In the present manuscript, we dissect the ultrastructural morphometry of both UP and ATG components in different cell compartments, alone and in combination to merge within the autophagoproteasome (APP), under the effects of various METH doses at different time intervals. A variety of techniques were used to investigate these effects encompassing plain light microscopy, confocal microscopy, transmission electron microscopy, Western blotting, and coimmunoprecipitation. In detail, we aimed to assess whether (i) the autophagoproteasome was operating in the DA-containing PC12 cell line, (ii) the autophagoproteasome was modified following METH exposure, (iii) the amount of this organelle was associated with the modulation of METH toxicity, and (iv) whether these phenomena depend on mTOR activity as tested during either mTOR inhibition or activation.

\section{Materials and Methods}

2.1. Cell Cultures. In the current study, we chose the rat pheochromocytoma PC12 cell line, since these cells are able to synthetize and release DA and they express DA receptors on their external membrane. This is key in the case of METH, which exerts its mechanisms of action mainly by affecting molecular targets, which regulate DA transmission. In fact, the presence of DA and DA receptors, as well as DA uptake mechanisms, renders PC12 cell lines closer to DA terminals compared with their ancestors (i.e., chromaffin cells of the adrenal medulla). This concept is reinforced by the presence of the isoform of monoamine oxidase (MAO) type A, which characterizes also DA neurons, contrasting with the established prevalence of MAO type B within chromaffin cells of the adrenal medulla. Therefore, PC12 cells represent a model to predict the neurotoxicity of METH on central DA neurons with significant implications for the treatment of neuropsychiatric and neurodegenerative disorders [49].

The PC12 cell line was obtained from a cell bank (IRCCS San Martino Institute, Genova). The cells were grown in RPMI 1640 medium (Sigma-Aldrich, St. Louis, MO, USA) supplemented with heat inactivated $10 \%$ horse serum (HS, Sigma) and 5\% fetal bovine serum (FBS, Sigma), penicillin (50 IU/ml)/streptomycin $(50 \mathrm{mg} / \mathrm{ml}$, Sigma), under standard culture conditions in a humidified atmosphere containing $5 \% \mathrm{CO}_{2}$ at $37^{\circ} \mathrm{C}$. Experiments took place during the log phase of cell growth. At this time, cells were seeded into cell culture plates and they were incubated at $37^{\circ} \mathrm{C}$ in $5 \% \mathrm{CO}_{2}$ for further 24 hours. In particular, for transmission electron microscopy (TEM) and coimmunoprecipitation experiments, $1 \times 10^{6}$ PC12 cells were seeded in culture dishes in a final volume of $5 \mathrm{ml}$. For Western blotting, $5 \times 10^{5}$ cells were seeded in six-well plates in a final volume of $2 \mathrm{ml} /$ well. Finally, for confocal microscopy experiments, $5 \times 10^{4}$ cells were grown on polylysine slides placed in 24 -well plates at a final volume of $1 \mathrm{ml} /$ well.

In order to study METH-induced toxicity, PC12 cells were treated with different doses of METH $(1 \mathrm{nM}, 10 \mathrm{nM}$, $100 \mathrm{nM}, 1 \mu \mathrm{M}$, and $10 \mu \mathrm{M})$ for 72 hours. In a second set of experiments, PC12 cells were treated with $1 \mu \mathrm{M}$ or $10 \mu \mathrm{M}$ of METH for different time exposures (12, 24, and 72 hours). A study from Melega et al. [50] reports data deriving from an i.v. intake of $1000 \mathrm{mg} /$ day METH in humans, approximately corresponding to $10 \mathrm{mg} / \mathrm{kg}$, which can produce neurotoxicity (i.e., loss of DA terminals and neurons) in mice. However, 
since the present study was designed to assess the ultrastructural effects of METH on specific subcellular organelles, apart from neurotoxicity, we chose METH doses from $1 \mu \mathrm{M}$ to $10 \mu \mathrm{M}$ based on the previous studies $[6,15,37]$. In our hands, at doses between 10 and $100 \mu \mathrm{M}$ of METH in PC12 cell lines, only a few cells survive, and this is further exacerbated by METH doses above $100 \mu \mathrm{M}[6,43]$. This is also due to intrinsic vulnerability of PC12 cells to DA-increasing agents, which explains such a discrepancy with DA neurons [49]. In fact, PC1 2 cells possess inherent features, which render these cells particularly sensitive to high doses of DA. These include (i) the presence of VMAT-1, which is less specific for the vesicular uptake of catecholamines when compared with its homolog VMAT-2 expressed in the brain, and (ii) low levels of the DAT, thus reduced cytosolic reuptake of DA. Thus, these cells have a limited ability to adapt the neurotransmitter synthesis and vesicle trafficking/release to the synaptic needs, which contrasts with the flexibility of DA neurons to respond appropriately to a releasing stimulus.

Further experiments were carried out to evaluate the effects produced on METH toxicity and APP components by the modulation of mTOR activity. In these experiments, cells were exposed to $100 \mathrm{nM}$ rapamycin and $50 \mathrm{mM}$ asparagine, alone or in combination with $10 \mu \mathrm{M}$ METH, for 72 hours. When it was combined with METH, rapamycin was added $2 \mathrm{~h}$ before $\mathrm{METH}$, while asparagine was administered $30 \mathrm{~min}$ before $\mathrm{METH}$. The doses of asparagine and rapamycin were selected based on the previous papers [32, 47]. However, to validate these doses in these experimental conditions, the inhibition or activation of mTOR activity for each compound was tested by measuring the downstream product pS6.

METH and asparagine were dissolved directly in the culture medium. Dilutions of rapamycin were obtained by a stock solution ( $1 \mathrm{mM}$ of rapamycin dissolved in the culture medium containing 10\% DMSO).

2.2. Transmission Electron Microscopy. PC12 cells were centrifuged at $1000 \mathrm{~g}$ for $5 \mathrm{~min}$. After removal of the supernatant, the pellet was rinsed in PBS before being fixed. The fixing procedure was carried out with a solution containing $2.0 \%$ paraformaldehyde and $0.1 \%$ glutaraldehyde in $0.1 \mathrm{M}$ PBS (pH 7.4) for $90 \mathrm{~min}$ at $4^{\circ} \mathrm{C}$. This aldehyde concentration minimally covers antigen epitopes, while fairly preserving tissue architecture. After removal of the fixing solution, specimens were postfixed in $1 \% \mathrm{OsO}_{4}$ for $1 \mathrm{~h}$ at $4^{\circ} \mathrm{C}$; they were dehydrated in ethanol and finally embedded in epoxy resin.

For ultrastructural morphometry, grids containing nonserial ultrathin sections ( $40-50 \mathrm{~nm}$ thick) were examined at TEM, at a magnification of $8000 x$. Several grids were analyzed in order to count a total number of 50-100 cells for each experimental group. In particular, when counting cell death, 50 cells per group were sampled, while 50 cells per group were sampled to carry out ultrastructural morphometry and immunogold counts; when counting APP, 100 cells per group were used. Each count was repeated at least 3 times by three blind observers.

Plain TEM was implemented by a postembedding immunocytochemistry procedure for antibodies against LC3 and
TABLE 1: Sources and references for antibodies reported in the present study.

\begin{tabular}{lc}
\hline Antibodies & References \\
\hline LC3 (Abcam) & {$[47,51-54]$} \\
LC3 (Sigma) & {$[55-57]$} \\
Proteasome 20S (Abcam) & {$[47,58-61]$} \\
Alpha-synuclein (BD Biosciences) & {$[62-66]$} \\
SQSTM1-p62 (Abcam) & {$[67-71]$} \\
Phospho-p70 S6 kinase (Thr421/Ser424) (Cell & {$[72-76]$} \\
Signaling Technologies) & \\
\hline
\end{tabular}

P20S, which were used as markers of ATG and UP pathways, respectively. Antibody specificity was assessed by a number of studies which were partially reported in Table 1 (extramural evidence), and they were routinely used for at least 10 years in our lab (intramural evidence) [51-76].

It is worth mentioning that LC3 and P20S antigens were chosen as markers of ATG vacuoles (LC3 alone) or APP vacuoles (LC3 combined with P20S) accordingly to the manuscript "Guidelines for the Use and Interpretation of Assays for Monitoring Autophagy (3rd Edition)" [48].

Sometimes, in order to validate the count for ATG vacuoles, beclin 1 was used instead of or in combination with LC3 for detecting early time points. No significant difference between LC3- and beclin 1-based counts was detected; thus, results fully express the amount of LC3. At the end of the plain TEM or immunocytochemistry procedure, ultrathin sections were stained with uranyl acetate and lead citrate, and they were finally examined using a JEOL JEM-100SX transmission electron microscope (JEOL, Tokyo, Japan).

2.2.1. Postembedding Immunocytochemistry. Fixing and postfixing solutions and the use of epoxy resin were validated in our previous studies for immunogold-based ultrastructural morphometry [47]. In fact, a combination of aldehydes, $\mathrm{OsO}_{4}$, and epoxy resin allows a minimal epitope covering, while preserving cell ultrastructure $[47,77,78]$. In particular, $\mathrm{OsO}_{4}$ binds to cell membranes, thus enhancing the contrast of cytosolic compartments, and it prevents the formation of membrane's artifacts, which may mimic vacuoles. Moreover, epoxy resin is advantageous over acrylic resin in preserving cell morphology.

Postembedding procedure was carried out on ultrathin sections collected on nickel grids, which were incubated on droplets of aqueous sodium metaperiodate $\left(\mathrm{NaIO}_{4}\right)$, for $30 \mathrm{~min}$, at room temperature in order to remove $\mathrm{OsO}_{4}$. $\mathrm{NaIO}_{4}$ is an oxidizing agent allowing a closer contact between antibodies and antigens by removing $\mathrm{OsO}_{4}$ [77]. This step improves the visualization of immunogold particles specifically located within a sharp context of cell integrity, and it allows the counting of molecules within specific cell compartments. Then, grids were washed in PBS and incubated in a blocking solution containing $10 \%$ goat serum and $0.2 \%$ saponin for $20 \mathrm{~min}$, at room temperature. Grids were then incubated with the primary antibody solution containing both rabbit anti-LC3 (Abcam, Cambridge, UK, diluted 1:50) and mouse anti-P20S (Abcam, Cambridge, 
UK, diluted $1: 50$ ), with $0.2 \%$ saponin and $1 \%$ goat serum in a humidified chamber overnight, at $4^{\circ} \mathrm{C}$. After washing in PBS, grids were incubated with the secondary antibodies conjugated with gold particles $(10 \mathrm{~nm}$ mean diameter, for gold particle anti-rabbit; $20 \mathrm{~nm}$ mean diameter, for gold particle antimouse, BB International), diluted 1:30 in PBS containing $0.2 \%$ saponin and $1 \%$ goat serum for $1 \mathrm{~h}$, at room temperature. Control sections were incubated with the secondary antibody only. After washing in PBS, grids were incubated on droplets of $1 \%$ glutaraldehyde for $3 \mathrm{~min}$; additional extensive washing of grids on droplets of distilled water was carried out to remove extensive salt traces and prevent precipitation of uranyl acetate.

2.2.2. Ultrastructural Morphometry. In order to distinguish vacuoles (ATG from APP) and to count immunogold particles (ranging from $10 \mathrm{~nm}$ to $20 \mathrm{~nm}$ ), observations were performed directly at TEM at a magnification of $8000 \mathrm{x}$ [79] since this represents the minimal magnification at which immunogold particles and all cell organelles can be concomitantly identified.

We started to count from a grid square corner in order to scan the whole cell pellet within that grid square, which was randomly identified. Assessments of vacuoles and measurement of immunogold particles were carried out according to Lenzi et al. [47].

Briefly, we counted the number of unstained vacuoles per cell as vacuoles with single, double, or multiple membranes possessing the same electron density of the surrounding cytoplasm or partly containing some electron dense structure. In each cell, we counted the total number of immunogold antiLC3 and/or anti-P20S particles placed either in the cytoplasm or within vacuoles and we expressed the number of immunogold particles as the mean per cell. Finally, we counted the number of APPs per cell as a single, double, and multiple membrane vacuoles, in which immunogold particles of LC3 $(10 \mathrm{~nm})$ and P20S $(20 \mathrm{~nm})$ were colocalized.

2.3. Light Microscopy. For light microscopy, PC12 cells were harvested and centrifuged at $800 \mathrm{~g}$ for $5 \mathrm{~min}$ to obtain a pellet, which was further resuspended in $0.5 \mathrm{ml}$ of the culture medium in order to obtain a dense cell suspension. This was layered on glass slide spinning at $15,000 \mathrm{~g}$ for $10 \mathrm{~min}$ by cytospin (Cytospin 4, Thermo Fisher).

2.3.1. Haematoxylin and Eosin Staining and Cell Count. Cells were fixed with $4 \%$ paraformaldehyde in PBS for $15 \mathrm{~min}$ and plunged in PBS and then in haematoxylin solution (Sigma) for $20 \mathrm{~min}$. Haematoxylin staining was stopped by washing in distilled water and followed by plunging cells in the eosin solution (Sigma) for a few min. After repeated washing to remove the excess of dye, cells were dehydrated in increasing alcohol solutions, clarified in xylene, and finally covered with the DPX mounting medium (Sigma). Cell count was performed at light microscopy at 40x magnification. Briefly, for each experimental group, the number of stained cells detectable after each specific treatment was counted and expressed as a percentage of the control group. These values represent the means of six independent cell counts.
Moreover, we counted the number of giant cells occasionally observed after $10 \mu \mathrm{M}$ METH. We considered as giant cells those owning a diameter higher than $14-15 \mu \mathrm{m}$. The amount of giant cells out of the total number of cells counted on the glass slide was expressed as a percentage, for each experimental group. The values represent the means of six independent cell counts.

2.3.2. Trypan Blue. For trypan blue staining, PC12 cells were seeded at a density of $1 \times 10^{4}$ cells/well and they were preincubated for $24 \mathrm{~h}$. After METH treatments, PC12 cells were collected and centrifuged at $800 \mathrm{~g}$ for $5 \mathrm{~min}$. The cell pellet was suspended in the culture medium, and $25 \mu \mathrm{l}$ of cell suspension was added to a solution of $1 \%$ trypan blue $(62.5 \mu \mathrm{l})$ and PBS $(37.5 \mu \mathrm{l})$. Cells were then incubated for $10 \mathrm{~min}$, at room temperature. Soon after, $10 \mu \mathrm{l}$ aliquot of this solution was counted at light microscopy using a Bürker glass chamber. Viable and nonviable cells were counted, and cell death was expressed as percentage of trypan blue frankly positive cells out of the total cells. The values represent the means of three independent cell counts.

2.4. Confocal Microscopy. PC12 cells were washed in PBS and fixed with paraformaldehyde $4 \%$ for $5 \mathrm{~min}$ at room temperature. Antigen retrieval was carried out in $100 \mathrm{mM}$ Tris- $\mathrm{HCl}$, $5 \%$ urea at $95^{\circ} \mathrm{C}$, for $10 \mathrm{~min}$. After washing in PBS, cells were permeabilized in $0.2 \%$ Triton X-100, for $10 \mathrm{~min}$. They were blocked in PBS containing 0.1\% Tween-20, supplemented with $1 \%$ bovine serum albumin (BSA) and $23 \mathrm{mg} / \mathrm{ml}$ of glycine, for $30 \mathrm{~min}$. Afterwards, cells were incubated overnight at $4^{\circ} \mathrm{C}$ in $1 \%$ BSA in PBS-T containing 1:50 anti-LC3 antibody (Abcam) and 1:30 anti-P20S (Abcam). Finally, cells were incubated for $1 \mathrm{~h}$ with fluorophore-conjugated secondary antibodies $(1: 200$; goat anti-rabbit Alexa 488 and goat anti-mouse Alexa 594, Molecular Probes, Life Technologies) in $1 \%$ BSA in PBS-T at room temperature. Then, cells were washed in PBS, and they were mounted in ProLong Diamond Antifade Mountant (Molecular Probes, Life Technologies). The analysis was performed using a Leica TCSSP 5 confocal laser scanning microscope (Leica Microsystems, Mannheim, Germany) using a sequential scanning procedure. Confocal images were collected every $400 \mathrm{~nm}$ intervals through the $z$ -axis of each section by means of $63 x$ oil lenses. Z-stacks of serial optical planes were analyzed using the Multicolor Package software (Leica Microsystems). Negative controls were carried out by omitting primary antibodies.

2.5. Coimmunoprecipitation Assay. PC12 cells were homogenized at $4^{\circ} \mathrm{C}$ in an ice-cold lysis buffer. One microliter of homogenates was used for protein determinations. $30 \mu \mathrm{g}$ of proteins from whole cell lysates was loaded to perform Western blotting before coimmunoprecipitation. $\beta$-Actin was used as a loading control for protein levels from the whole cell lysates, on which immunoprecipitation of LC3 was then performed.

Proteins $(800 \mu \mathrm{g})$ were incubated at $4^{\circ} \mathrm{C}$ overnight with primary rabbit anti-LC3 antibody $(2 \mu \mathrm{g}$ for each sample; Sigma-Aldrich, Milan, Italy). The antibody/antigen complex was pulled out of the sample using protein A-Sepharose 
beads. This process isolated the protein of interest from the rest of the sample. Proteins were separated on sodium dodecyl sulphate-polyacrylamide gel (12\%) and transferred on immuno-PVDF membrane (Bio-Rad, Milan, Italy) for $1 \mathrm{~h}$. Filter was blocked for $1 \mathrm{~h}$ in Tween-20 Tris-buffered saline (TTBS) (100 mM Tris- $\mathrm{HCl}, 0.9 \% \mathrm{NaCl}, 1 \%$ Tween 20, pH 7.4) containing 5\% nonfat dry milk. Blot was incubated at $4{ }^{\circ} \mathrm{C}$ overnight with mouse monoclonal primary antibody anti-P20S (1:100, Abcam), mouse monoclonal anti-alphasynuclein ( $1: 1000, \mathrm{BD}$ Biosciences), and rabbit monoclonal anti-SQSTM1 (anti-p62, 1:1000, Abcam, Milan, Italy); it was washed 3 times with the TTBS buffer and then incubated for $1 \mathrm{~h}$ with secondary peroxidase-coupled antibody (antimouse, 1:7000; anti-rabbit, 1:7000; Calbiochem, Milan, Italy). Then, blot was stripped with a solution of distilled water and $3.5 \%$ acetic acid in the presence of $1 \% \mathrm{NaCl} 5 \mathrm{M}$. Blot was kept in this solution for $20 \mathrm{~min}$, and then, it was washed in TTBS (8 washes for $5 \mathrm{~min}$ ). Finally, to verify the correct immunoprecipitation, blot was incubated with primary rabbit anti-LC3 antibody (1:6000, Sigma-Aldrich), for $1 \mathrm{~h}$, at room temperature. Filter was washed 3 times with the TTBS buffer and then incubated for $1 \mathrm{~h}$ with secondary peroxidase-coupled antibody (anti-rabbit, 1:7000; Calbiochem, Milan, Italy). Immunostaining was revealed by enhanced chemiluminescence (GE Healthcare, Milan, Italy). The total amount of proteins measured through optical density was normalized for total $\beta$-actin, which was measured in whole cell lysates, since $\beta$-actin is not present in LC3 immunoprecipitates. Thus, readers should consider that such a normalization could not refer to the immunoprecipitated blotted proteins, but rather to the total amount of proteins in the very same cells used to carry out the immunoprecipitate.

2.6. Western Blotting. PC12 cells were lysed in a buffer (100 mM Tris- $\mathrm{HCl}, \mathrm{pH} 7.5,5 \mathrm{M} \mathrm{NaCl}, 0.5 \mathrm{~m}$ EDTA, $10 \%$ SDS, 1\% NP40, IGEPAL), containing protease and phosphatase inhibitor, and centrifuged at $15,000 \mathrm{~g}$ for $20 \mathrm{~min}$ at $4^{\circ} \mathrm{C}$. The supernatant was collected, and protein concentration was determined using a protein assay kit (Sigma). Samples containing $40 \mu \mathrm{g}$ of total proteins were solubilized and electrophoresed on a $12 \%$ sodium dodecyl sulphate(SDS-) polyacrylamide gel. Following electrophoresis, proteins were transferred to the nitrocellulose membrane (Bio-Rad Laboratories, MI, Italy). The membrane was immersed in a blocking solution (3\% nonfat dried milk in $20 \mathrm{mM}$ Tris and $137 \mathrm{mM} \mathrm{NaCl}$ at $\mathrm{pH} 7.6$ containing $0.05 \%$ Tween-20) for $2 \mathrm{~h}$ on a plate shaker. Subsequently, the membrane was incubated with mouse anti-pS6 primary antibody (1:2000; Millipore, Burlington, MA, USA) overnight at $4^{\circ} \mathrm{C}$ on the plate shaker. Blot was probed with horseradish peroxidase-labeled secondary antibodies, and the bands were visualized with enhanced chemiluminescence reagents (Bio-Rad Laboratories). Image analysis was carried out by ChemiDoc System (Bio-Rad Laboratories).

2.7. Statistics. For ultrastructural morphometry data were given as an absolute number concerning the following measurements: (i) unstained vacuoles, (ii) LC3-positive vacuoles, (iii) P20S-positive vacuoles, (iv) LC3 + P20S-positive vacuoles (APP), and (v) immunogold particles (including LC3 and P20S). Ratios were used to express (i) the number of LC3 immunogold particles within vacuoles out of the number of cytoplasmic LC3 immunogold particles and (ii) the number of P20S immunogold particles within vacuoles out of the number of cytoplasmic P20S immunogold particles. All data were reported as the means \pm SEM per cell from 50 cells per group in all counts but the LC3 + P20S which was expressed as the means \pm SEM from 100 cells per group.

Data on the amount of cell death were expressed as the percentage of the mean \pm SEM dead cells out of the total cell number in each grid being analyzed (i.e., 5 total grids, each containing at least 10 cells, for a total of 50 cells for each experimental group).

For confocal microscopy, the amount of P20S + LC3 puncta was counted. Values were expressed as the mean number of puncta \pm SEM per cell counted in each slide in two separate experiments (each one carried out in duplicate).

For Western blot optical density was expressed as the means \pm SEM calculated in six separate experiments.

All statistical analyses were carried out by using one-way analysis of variance, ANOVA, followed by Sheffè's post hoc analysis. Null hypothesis (H0) was rejected for $p \leq 0.05$.

\section{Results and Discussion}

3.1. Dose and Time Dependencies of METH-Induced Unstained Vacuoles. Confirming previous data, METH administration for $72 \mathrm{~h}$ filled catecholamine cells with vacuoles, as reported in representative micrographs (Figure 1(a)) and counted in the graph of Figure 1(b). As measured in Figure 1(b), unstained vacuoles increase dose-dependently within a wide range of $\mathrm{METH}$ doses (from $1 \mathrm{nM}$ up to $1 \mu \mathrm{M})$. At the dose of $1 \mu \mathrm{M}$, the number of $\mathrm{METH}$-induced unstained vacuoles reached the peak. Whereas, for the highest dose of METH $(10 \mu \mathrm{M})$, the number of unstained vacuoles dropped down to levels measured following low METH doses ( $1 \mathrm{nM}$ and $10 \mathrm{nM}$ ). This suggests that at $10 \mu \mathrm{M}$ METH dose, toxicity occludes the development of novel intracellular structures, even in spared cells. Therefore, the doses of METH $1 \mu \mathrm{M}$ and $10 \mu \mathrm{M}$ were chosen for the time dependence study. As reported in representative micrographs of Figure 1(c), a time-dependent increase of unstained vacuoles was produced by $\mathrm{METH}$ at the $1 \mu \mathrm{M}$ dose from $12 \mathrm{~h}$ up to $72 \mathrm{~h}$. These effects were evidenced by staining with arrows the unstained vacuoles in each experimental condition to relate representative pictures to counts reported in the graph in Figure 1(d). As expected, even the dose of $10 \mu \mathrm{M}$ METH at $72 \mathrm{~h}$ timedependently increases the number of unstained vacuoles (Figure 1(f)). This was evident in representative micrographs of Figure 1(e); we investigated the effects of such a METH dose at earlier time intervals (representative pictures of Figure 1(e)). These effects were evidenced by staining with arrows the unstained vacuoles at each time interval to relate representative pictures to counts reported in the graph in Figure 1(f). The number of unstained vacuoles is consistent with the time course and dose dependency of multilamellar 


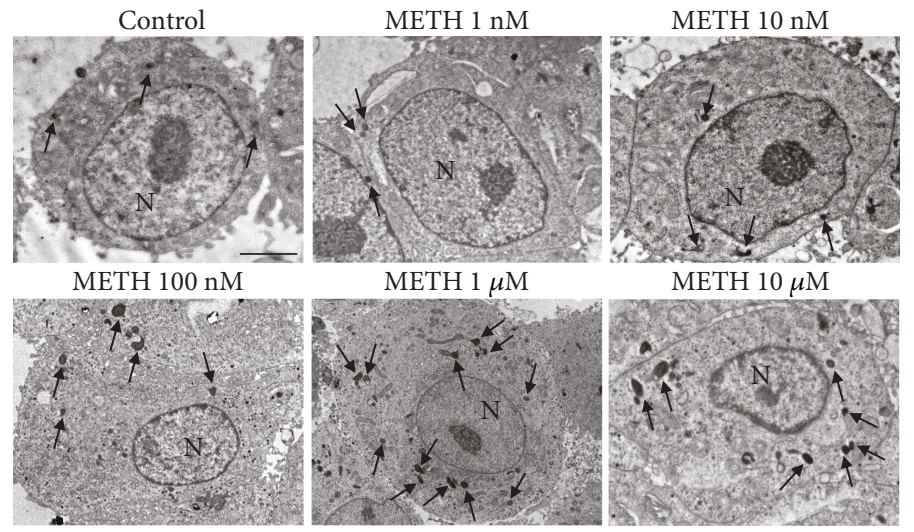

(a)
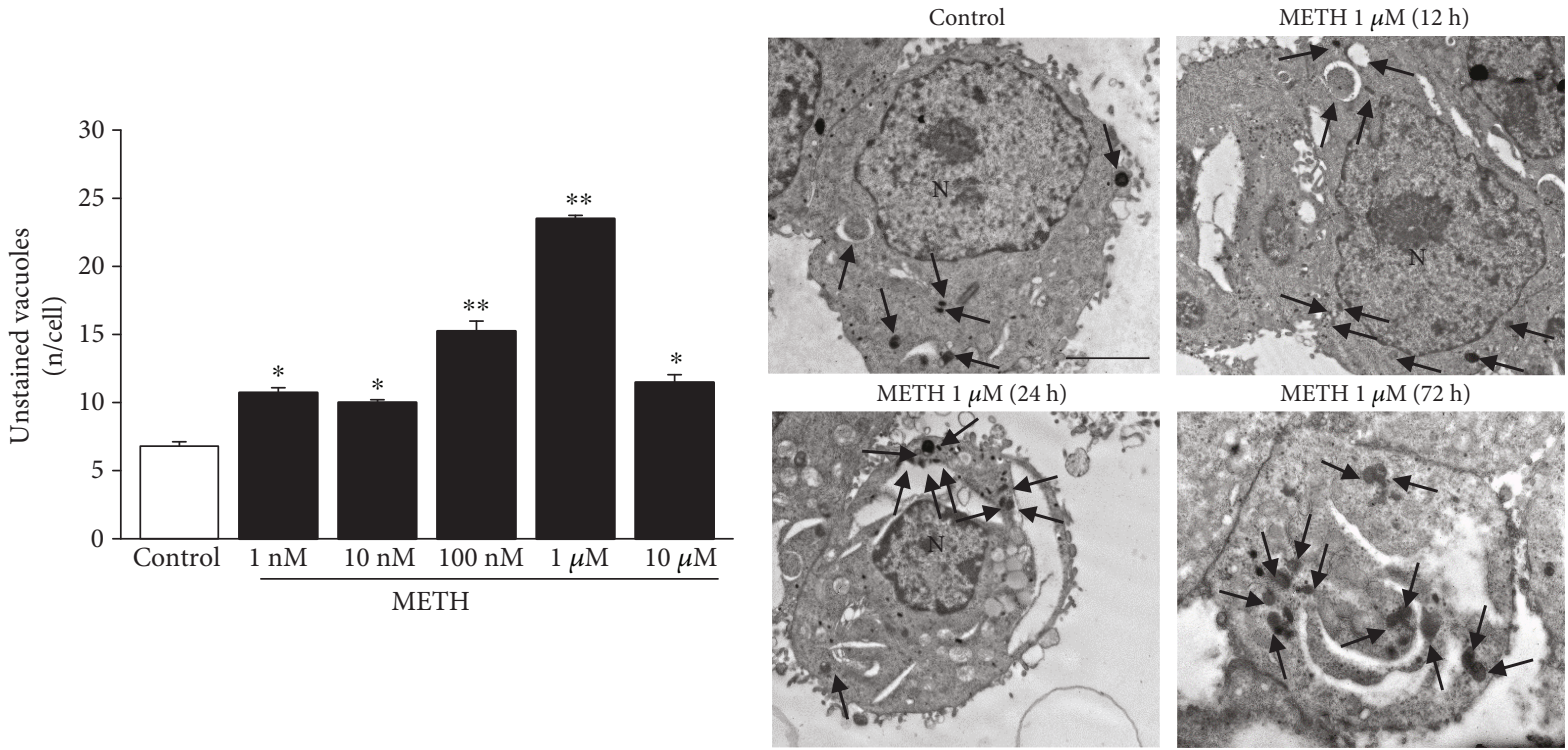

(b)

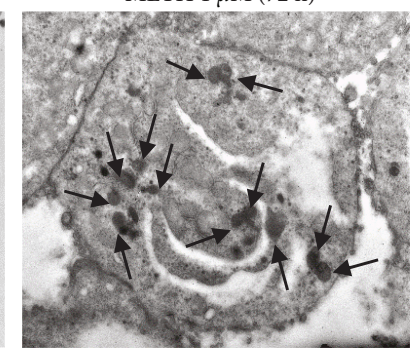

(c)
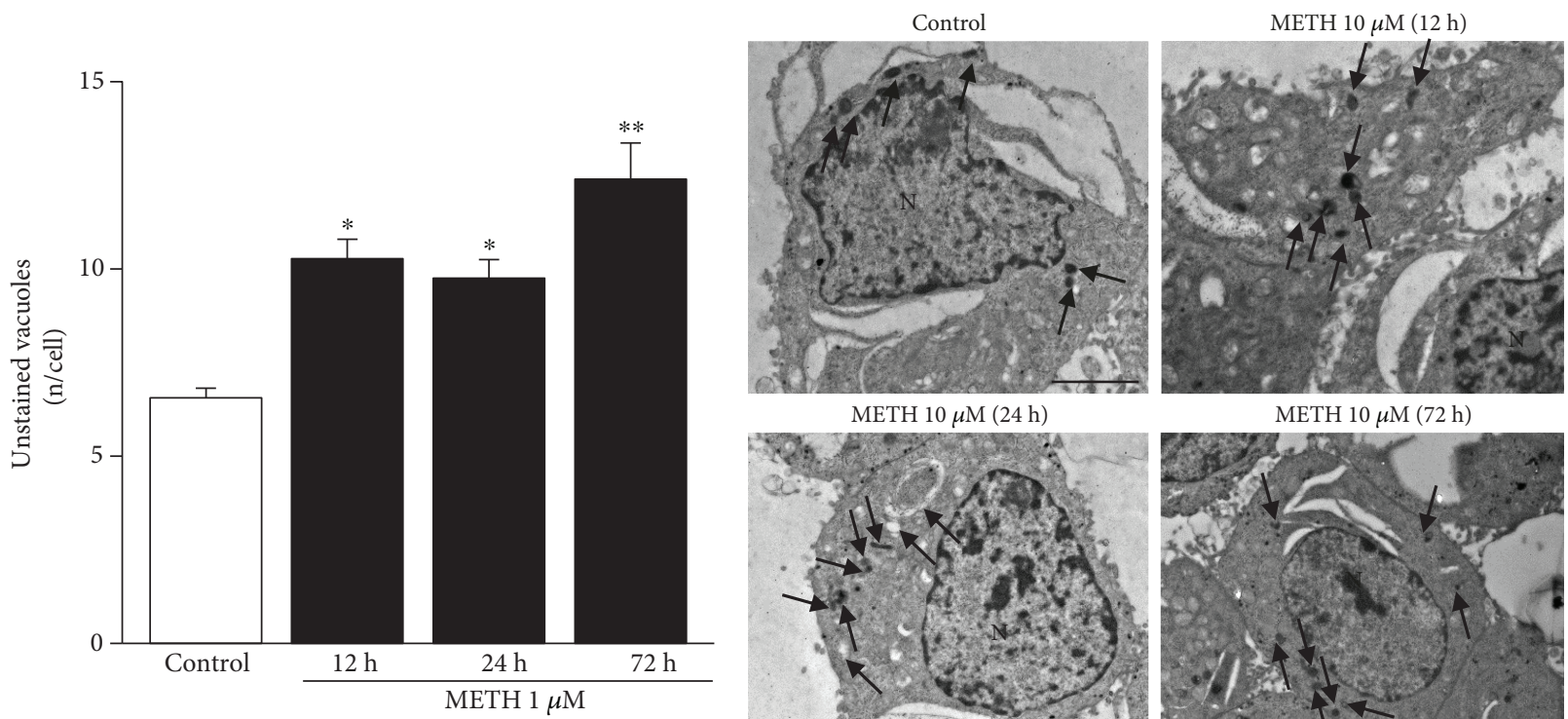

METH $10 \mu \mathrm{M}(24 \mathrm{~h})$

METH $10 \mu \mathrm{M}(72 \mathrm{~h})$
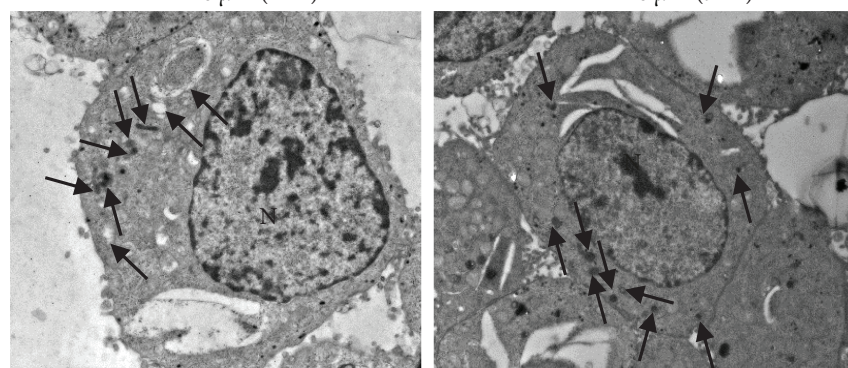

(d)

(e)

Figure 1: Continued 


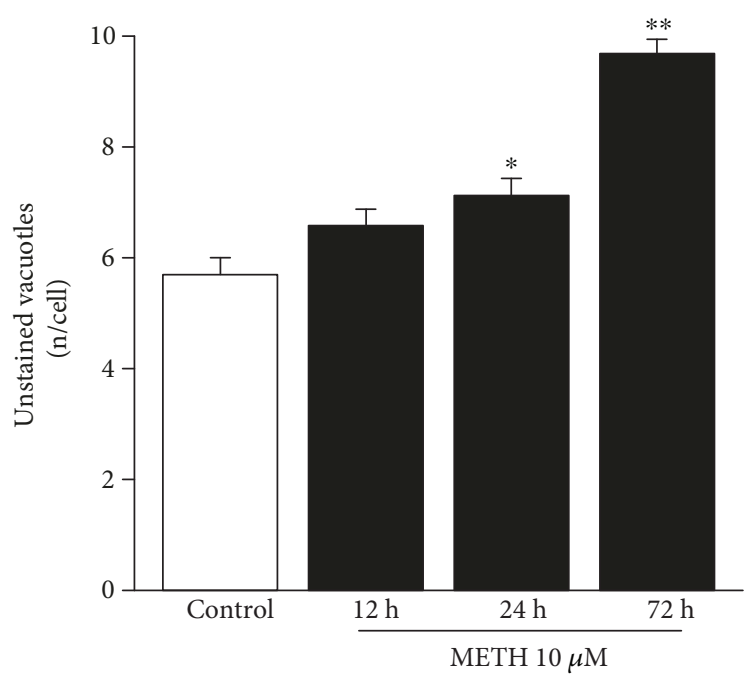

(f)

FIGURE 1: METH increases the amount of unstained vacuoles dose- and time-dependently. (a) Dose-dependent representative pictures of unstained vacuoles (arrows) of control and METH at $72 \mathrm{~h}$ treated cells at different doses. (b) Dose-dependent graph of unstained vacuoles per cell at $72 \mathrm{~h}$. (c) Time-dependent representative pictures of unstained vacuoles (arrows) of control and $1 \mu \mathrm{M}$ METH-treated cells. (d) Time-dependent graph of unstained vacuoles per cell of control and $1 \mu \mathrm{M}$ METH-treated cells. (e) Time-dependent representative pictures of unstained vacuoles (arrows) of control and $10 \mu \mathrm{M}$ METH-treated cells. (f) Time-dependent graph of unstained vacuoles per cell of control and $10 \mu \mathrm{M}$ METH-treated cells. Values are given as the mean number of unstained vacuoles, which were counted in 50 cells per group. Error bars represent the standard error of the mean. ${ }^{*} p \leq 0.05$ vs. control; ${ }^{* *} p \leq 0.05$ vs. other groups. $\mathrm{N}=$ nucleus. Scale bar $=1 \mu \mathrm{m}$.

bodies produced by METH, which we previously described under a different name (whorls) in this cell line [6].

\subsection{Dose and Time Dependencies of METH-Induced Cell} Death. When assessing the effects produced by a $10 \mu \mathrm{M}$ dose of METH, there was a dramatic increase (roughly by half) in the amount of cell loss compared with controls and occasionally, giant cells appeared, which were never observed in controls (representative H\&E staining of Figures 2(a) and 2(b); graph of Figure 2(c)). The counts for surviving cells carried out at H\&E staining revealed a dose- and time-dependent decrease in cell survival (graphs of Figures 2(d) and 2(e), respectively). This was dramatic at $72 \mathrm{~h}$ following $10 \mu \mathrm{M}$ METH. These same results were reproduced by trypan blue-positive counts for dying cells, which confirmed a dose- and time-dependent increase in dying cells (graphs of Figures 2(f) and 2(g), respectively). A similar phenomenon (cell death in the same range of doses and times induced by METH administration) was detected at TEM (representative TEM micrographs of Figures $2(\mathrm{~g})$ and $2(\mathrm{~h})$, respectively). The count of dying cells (either necrotic or apoptotic) at TEM for METH and controls (Figures 2(h) and 2(i), respectively) was overlapping with that reported for trypan blue staining. Remarkably dying cells were higher than controls also following the dose of $1 \mu \mathrm{M}$ (at $72 \mathrm{~h}$, Figures $2(\mathrm{j})$ and $2(\mathrm{k})$ ). The pronounced toxicity induced by $10 \mu \mathrm{M}$ METH is likely to impair cell metabolism even in spared cells, which when analyzed at $72 \mathrm{~h}$ own much less vacuoles compared with other doses.
3.3. METH Alters Dose and Time Dependency of the Amount and Placement of LC3 Particles. In order to identify ATG and UP components within METH-treated cells, we carried out ultrastructural morphometry by using $10 \mathrm{~nm}$ immunogold particles to reveal LC3, while $20 \mathrm{~nm}$ immunogold particles were used to stain P20S. Following METH administration, an increase in LC3-stained vacuoles was detected starting at the dose of $100 \mathrm{nM}$ METH, while no increase compared with controls was counted in a lower range of doses (between $1 \mathrm{nM}$ and $10 \mathrm{nM}$, Figure 3(a)). This was quite unexpected since the count of unstained vacuoles provided in Figure 1(b) indicates a significant increase (almost two-fold) compared with controls even at the dose of $1 \mathrm{nM}$ METH. This is a key point, since unstained vacuoles are considered to correspond to pure ATG vacuoles. Thus, one would expect an overlapping between unstained and LC3-positive vacuoles. Such a discrepancy leaves the issue open on which the nature of METH-induced unstained vacuoles might be. In fact, these vacuoles were induced by METH administration since they increased two-fold compared with controls at the dose of $1 \mathrm{nM}$ and $10 \mathrm{nM}$ METH.

A lack of LC3 staining in these vacuoles for low METH doses suggests that these may not correspond to authentic ATG vacuoles, although they increase two-fold with respect to controls. Although the nature of these unstained vacuoles remains to be defined, the possibility exists that LC3 particles moving within ATG vacuoles remain undetected for these low METH doses. However, as shown in the graph of Figure 3(b), total LC3 particles in the cell for $1 \mathrm{nM}$ and $10 \mathrm{nM}$ METH do not increase either. This indicates a lack of ATG induction for low METH doses. Another possibility 


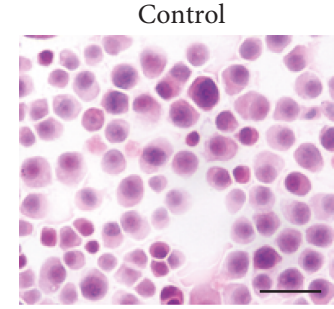

(a)

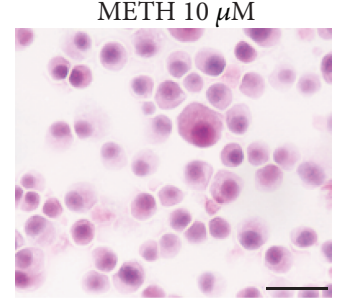

(b)

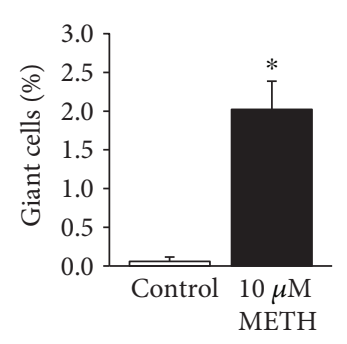

(c)

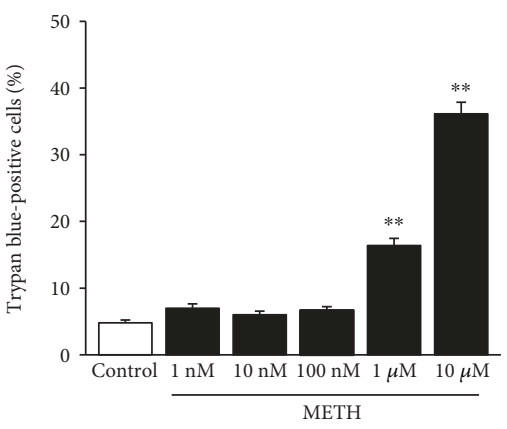

(f)

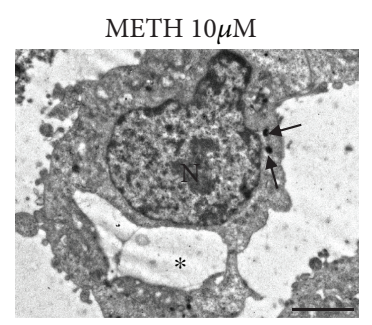

(i)

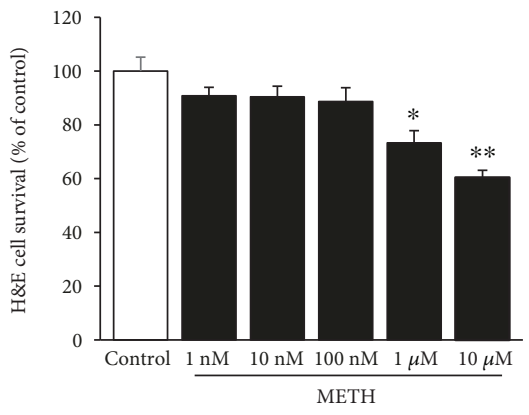

(d)

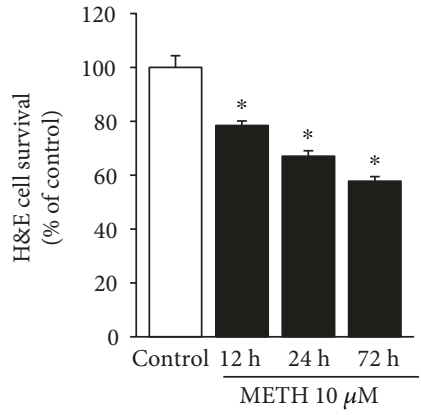

(e)

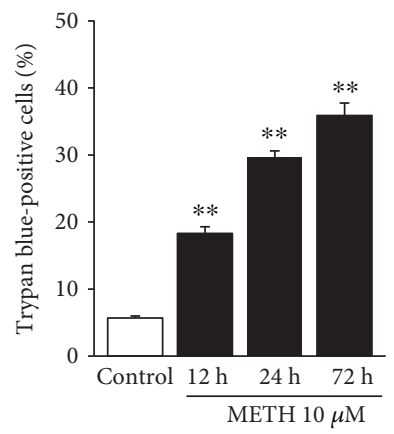

(g)

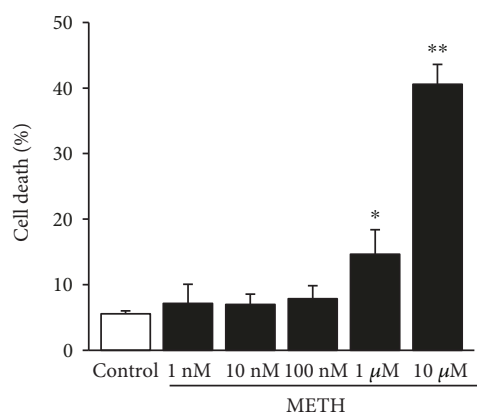

(j)

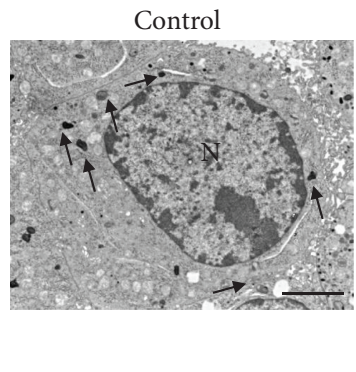

(h)

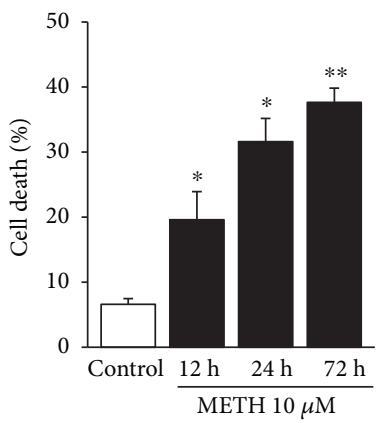

(k)

Figure 2: METH induces cell death time- and dose-dependently with a maximal effect at the $1 \mu \mathrm{M}$ and $10 \mu \mathrm{M}$ doses. (a) Representative H\&Estained picture from controls. (b) Representative H\&E-stained picture following $10 \mu \mathrm{M}$ METH at $72 \mathrm{~h}$. (c) Graph reporting the percentage of giant cells counted in H\&E-stained total cells from controls and METH at $72 \mathrm{~h}$. (d) Dose-dependent graph of H\&E-stained cells from control and METH at $72 \mathrm{~h}$. (e) Time-dependent graph of H\&E-stained cells from control and $10 \mu \mathrm{M}$ METH-treated cells. (f) Dose-dependent graph of trypan blue-stained cells from control and METH at $72 \mathrm{~h}$. (g) Time-dependent graph of trypan blue-stained cells from control and $10 \mu \mathrm{M}$ METH-treated cells. (h) Representative micrograph from a control cell. (h) Representative micrograph from a control cell. (i) Representative micrograph from a METH cell at $72 \mathrm{~h}$. (j) Dose-dependent graph of cell death from control and METH at $72 \mathrm{~h}$. (m) Time-dependent graph of cell death from control and $10 \mu \mathrm{M}$ METH-treated cells. For the graphs in (c)-(g), values are given as the percentage of cell counted in two triplicates $(n=6)$. For the graphs in $(\mathrm{j})$ and $(\mathrm{k})$, values are given as the percentage of cell counted on 5 grids. Error bars represent the standard error of the mean. ${ }^{*} p \leq 0.05$ vs. control, ${ }^{* *} p \leq 0.05$ vs. other groups. Arrows point to vacuoles; asterisk $\left({ }^{*}\right)$ indicates a large vacuole. $\mathrm{N}=$ nucleus. Scale $\operatorname{bar}=23.4 \mu \mathrm{m}(\mathrm{a}, \mathrm{b})$ and $2 \mu \mathrm{m}(\mathrm{h}, \mathrm{i})$. 


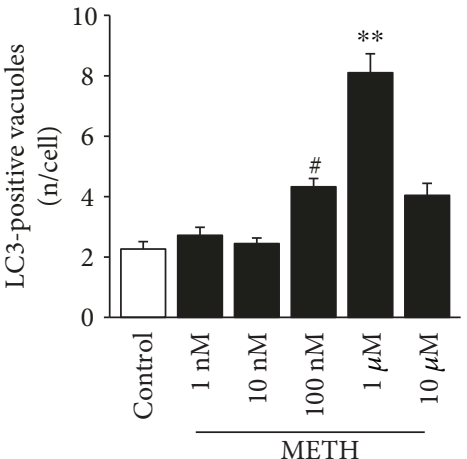

(a)

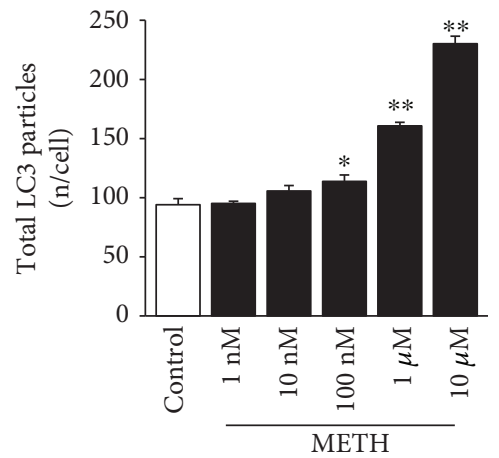

(b)

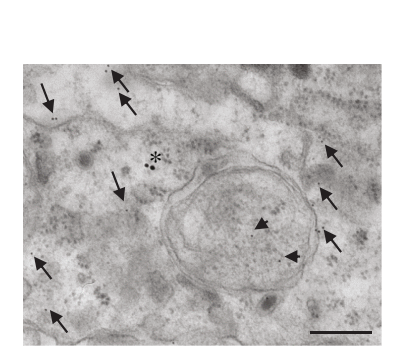

(c)

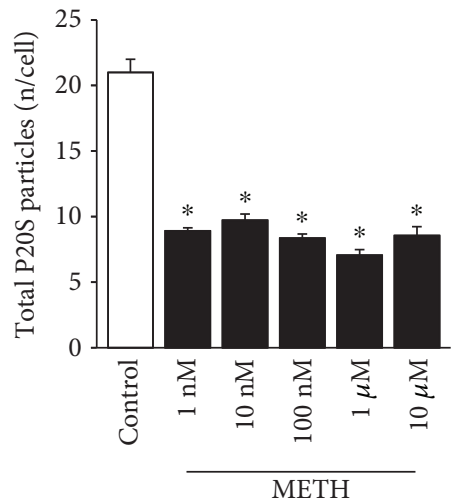

(f)

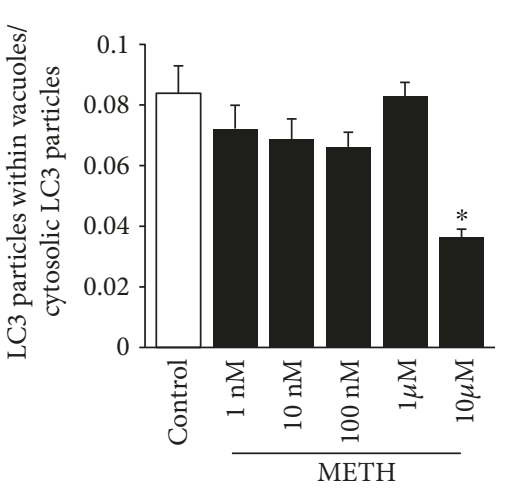

(d)

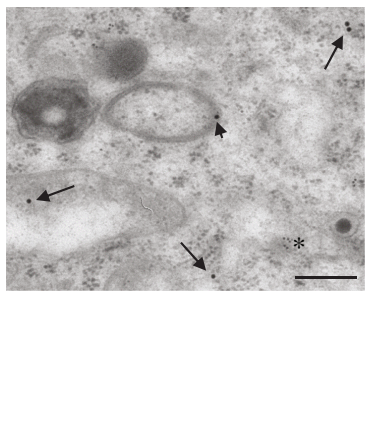

(g)

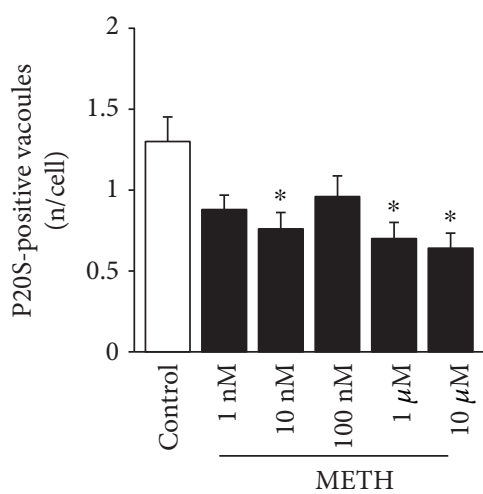

(e)

FIGURE 3: METH alters the amount and placement of LC3 and P20S particles dose-dependently, with P20S being more sensitive than LC3. (a) Dose-dependent graph of the number of LC3-positive vacuoles per cell from controls and METH at $72 \mathrm{~h}$. (b) Dose-dependent graph of total LC3 particles per cell from controls and METH at $72 \mathrm{~h}$. (c) Representative micrograph of LC3-positive vacuole from $10 \mu \mathrm{M} \mathrm{METH}$ at $72 \mathrm{~h}$. (d) Dose-dependent graph of the ratio between the numbers of LC3 particles within vacuoles with respect to cytosolic LC3 particles from controls and METH at $72 \mathrm{~h}$. (e) Dose-dependent graph of the number of P20S-positive vacuoles per cell from controls and METH at $72 \mathrm{~h}$. (f) Dosedependent graph of total P20S particles per cell from controls and METH at $72 \mathrm{~h}$. (g) Representative micrograph of P20S-positive vacuoles from $10 \mu \mathrm{M}$ METH at $72 \mathrm{~h}$. (h) Dose-dependent graph of the ratio between the numbers of P20S particles within vacuoles with respect to cytosolic P20S particles from controls and METH at $72 \mathrm{~h}$. Values are given as the mean number of LC3 or P20S particles and vacuoles counted in 50 cells per group. Error bars represent the standard error of the mean. ${ }^{*} p \leq 0.05$ vs. control; ${ }^{* *} p \leq 0.05$ vs. other groups; ${ }^{\#} p \leq$ 0.05 vs. control and $1 \mathrm{nM}$ and $10 \mathrm{nM}$ METH. Arrows point to free cytosolic LC3 (10 nm) or P20S (20 nm); arrowheads point to LC3 $(10 \mathrm{~nm})$ or P20S $(20 \mathrm{~nm})$ within vacuoles; asterisk $\left({ }^{*}\right)$ indicates P20S in the cytosol (c) and LC3 in the cytosol $(\mathrm{g})$. Scale bar $=200 \mathrm{~nm}$.

deals with the dynamics of ATG vacuoles, which could maturate before LC3 is increased. This hypothesis remains unlikely, since other markers, such as beclin 1, which stains ATG vacuoles earlier than LC3, do not provide any staining either. Moreover, LC3 staining is a gold standard to define autophagosomes, and $72 \mathrm{~h}$ should be enough to complete the process. Instead, even at this time interval for low ( $1 \mathrm{nM}$ and $10 \mathrm{nM}) \mathrm{METH}$ doses, LC3 particles do not increase in any cell compartments including the cytosol. This suggests that $1 \mathrm{nM}$ and $10 \mathrm{nM}$ METH do not really increase 
ATG. Therefore, unstained vacuoles, which minimally occur in control cells and selectively increase following very low METH doses, are likely to belong to other pathways (such as the exosomal compartment). This hypothesis is currently under investigation in the lab. Vacuolar compartments other than ATG may be recruited for low METH doses. It is likely that DA turnover promoted by METH increases vesicle recycling, which may account for these unstained vacuoles. On the other hand, the lowest effects of METH on membrane trafficking may affect other compartments such as retromers or exosomes, which are more bound to cell release than ATG activation.

The increase in vacuoles measured for doses above $10 \mathrm{nM}$ corresponds to LC3-positive (ATG) vacuoles. Data on the amount of LC3-positive vacuoles (shown in representative Figure 3(c)) parallels data on LC3 particles reported in the graph of Figure 3(b). In fact, they increase significantly only at the dose of $100 \mathrm{nM}$, while they do not differ from controls at low METH doses ( $1 \mathrm{nM}$ and $10 \mathrm{nM}$ METH). Thus, METH increases LC3 particles (Figure 3(b)) and LC3-positive vacuoles (Figure 3(a)) only at doses higher than $10 \mathrm{nM}$, although no compartmentalization of LC3 within vacuoles is produced by any dose of METH (graph of Figure 3(d)). In contrast, the trend indicates a dispersion rather than a polarization of LC3 particles from cell vacuoles towards the cytosol. This is indicated by the finding that the ratio of vacuolar vs. cytosolic LC3 particles following METH decreases dose-dependently (Figure 3(d)), which indicates a METH-induced loss of LC3 compartmentalization. Such an uncoupling between LC3 and ATG vacuoles is a novel finding in METH toxicity. In fact, so far, METH was thought to impair ATG machinery by engulfing ATG vacuoles, which become stagnant and filled with LC3. The present data show that, under METH, ATG vacuoles are impaired already in their maturation. In fact, for low METH doses, LC3 is not increased, while for higher METH doses, LC3 increases more in the cytosol than within vacuoles. It looks like that in these conditions (METH doses up to $1 \mu \mathrm{M}$ ), the drive which polarizes LC3 towards the ATG machinery is weakened. At $10 \mu \mathrm{M} \mathrm{METH}$, there is a further drop in the ratio between vacuolar and cytosolic LC3 particles, which is likely to be due to a concomitant loss of cell ability to build organelles for toxic METH doses. This latter finding is confirmed by the fact that $10 \mu \mathrm{M}$ METH strongly increases free LC3 particles compared with the dose of $1 \mu \mathrm{M}$, but the number of LC3-positive ATG vacuoles at $10 \mu \mathrm{M}$ is roughly a half of that counted at $1 \mu \mathrm{M}$.

These observations, despite being unexpected, provide also novel methodological insights into ATG. In fact, when using confocal microscopy following high METH doses, there is a strong increase in LC3 immunofluorescence, which is routinely interpreted as produced by stagnant vacuoles. However, ultrastructural morphometry demonstrates that an increase in LC3 immunostaining is indeed driven by free cytosolic noncompartmentalized LC3 rather than by vacuolar LC3.

We may summarize these latter data by stating that, under METH administration, there is a loss of compartmentalization of LC3 particles within vacuoles, despite an increased amount of both LC3 particles and vacuoles per se, which represents a novel insight in ATG and METH toxicity.

This leads to reconsider the significance of densely fluorescent LC3 spots detected at confocal microscopy following METH $[16,80]$. The stoichiometric counts at TEM demonstrate that a greater contribution is provided by free cytosolic LC3. This is representatively evidenced in micrograph of Figure 3(c), and it is remarked by the ratio between compartmentalized LC3 particles in ATG vacuoles and free cytosolic LC3 particles (graph of Figure 3(d)). This demonstrates a lack of METH-induced LC3 compartmentalization with a trend towards "METH-induced LC3 dispersion." This is frankly evident for a neurotoxic dose of METH $(10 \mu \mathrm{M})$ where a loss of fine subcellular compartments take place. As discussed for Figure 1(b), this is likely to reflect a degeneration of the subcellular trim of spared cells, which organize protein trafficking, where the ability to create various cell compartments is reduced.

3.4. METH Alters the Amount and Placement of P20S Particles. When counting P20S-positive vacuoles, these were consistently decreased compared with controls for all METH doses (Figures 3(e) and 3(g)). These findings were reproduced when counting P20S immunogold particles, which were markedly decreased following all METH doses (ranging between $1 \mathrm{nM}$ and $10 \mu \mathrm{M}$, Figure 3(f)). Remarkably, this was replicated even for the highest dose of $10 \mu \mathrm{M} \mathrm{METH}$, which was shown to suppress compartmentalization of LC3 within vacuoles (Figure 3(d)). It is likely that such a discrepancy is related to a different sensitivity of P20S compared with LC3 to the effects of METH. Again, no polarization of P20S towards vacuoles was induced by $\mathrm{METH}$, which left the ratio unmodified between $\mathrm{P} 20 \mathrm{~S}$ particles within vacuoles and cytosolic P20S particles compared with controls (Figure 3(h)), although the trend was different compared with LC3.

It is surprising that the effects induced by METH on the number of the ATG marker LC3 follow a different dose-response curve compared with the effects induced on the number of the UP marker P20S. In fact, in the range of $1 \mathrm{nM}$ to $10 \mathrm{nM}$ doses, no alterations were produced by METH in the number of LC3 immunogold particles (Figure 3(b)), while at the dose of $1 \mathrm{nM}$ of METH, the reduction of P20S immunogold particles was already maximal (roughly, a half of controls, Figure 3(f)). This suggests that the biochemical pathways involved (regulating either ATG or UP) possess a different dose-response curve being the UP maximally affected already at the lowest dose of METH. Thus, the P20S protein component is markedly sensitive to doses of METH, which are likely to be in the picomolar range.

As previously discussed, the lowest dose of METH ( $1 \mathrm{nM})$ doubled the number of unstained vacuoles without affecting neither LC3 particles nor LC3 vacuoles. In contrast, this very same dose reduced roughly to a half both P20S particles and P20S-positive vacuoles. It is worth noting that this METH dose is sufficient to double the DA release in PC12 cells [6]. Thus, it is likely that an increased amount of free DA may already impair the P20S proteasome. This is consistent with our previous study showing that, at the dose of $1 \mathrm{nM}$ of 


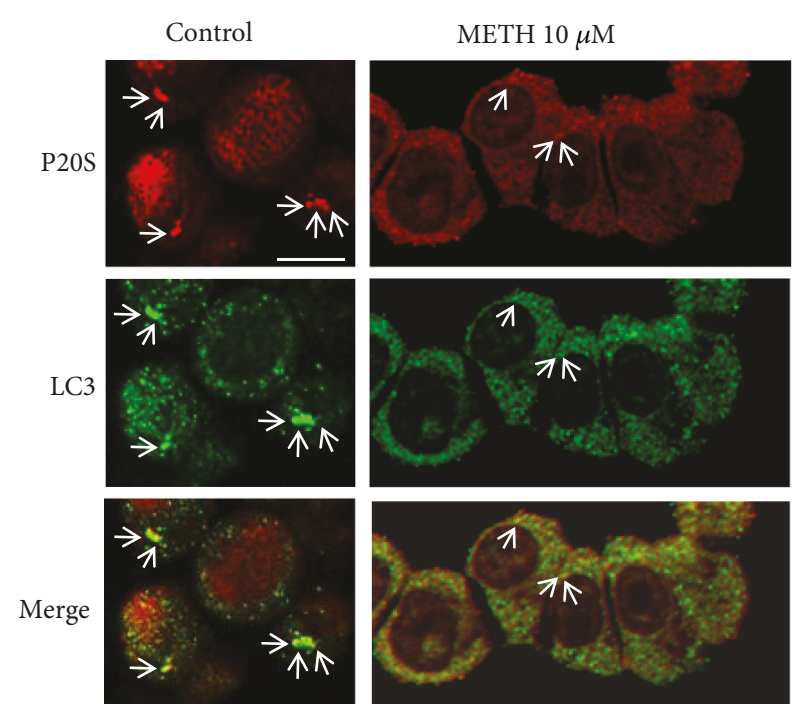

(a)

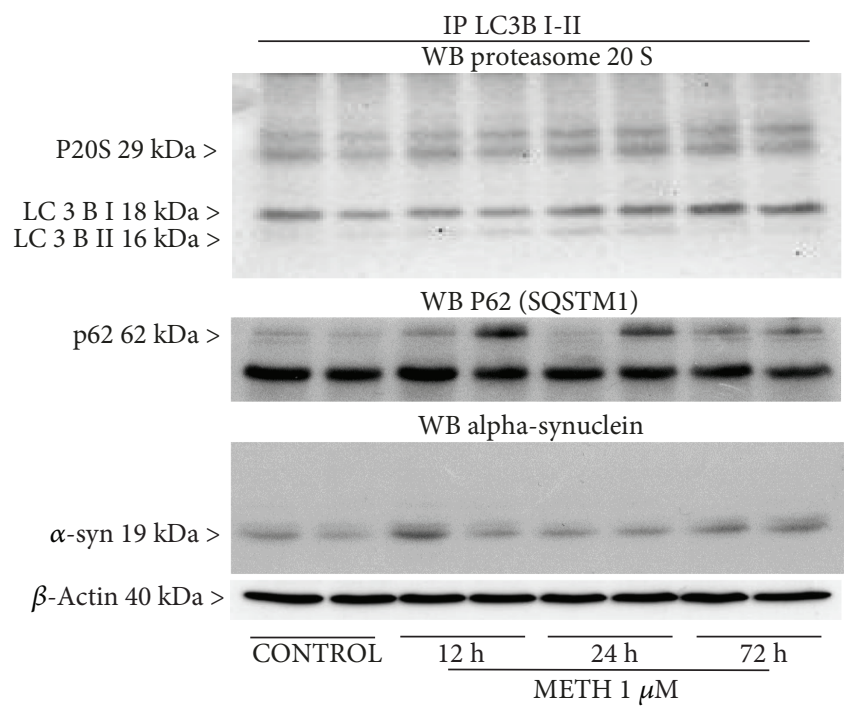

(c)

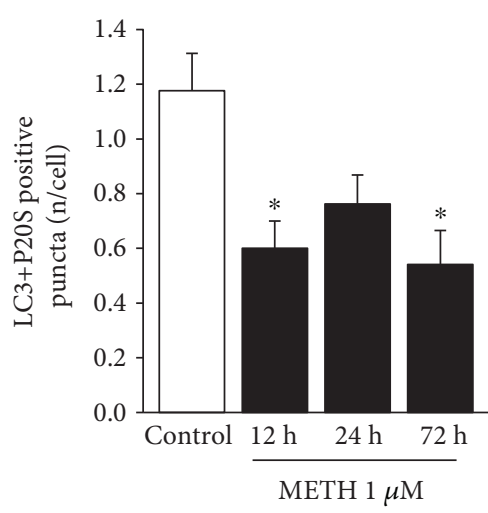

(b)
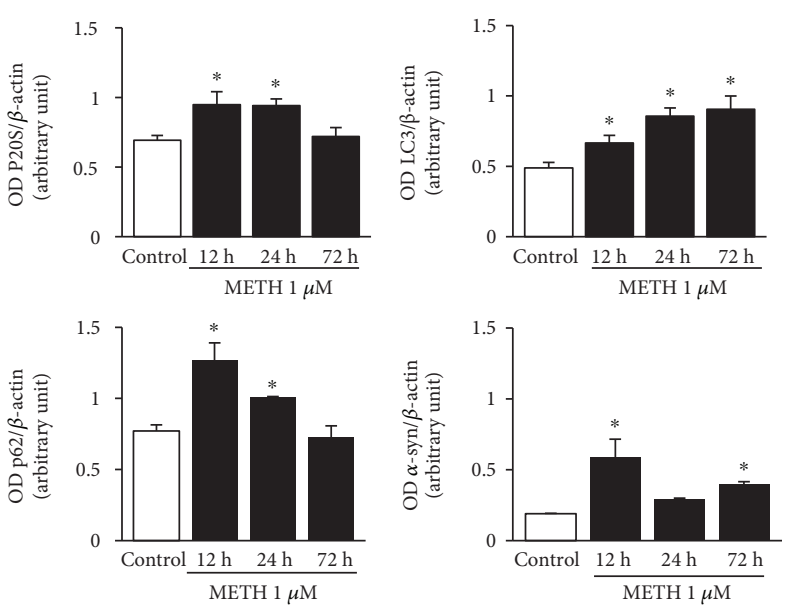

(d)

FIGURE 4: METH reduces the occurrence of the autophagoproteasome (APP) which hosts LC3, P20S, p62, and alpha-synuclein. (a) Representative immunofluorescence from controls and METH at $72 \mathrm{~h}$. (b) Time-dependent graph of the number of LC3 + P20S-positive puncta per cell from control and METH at $1 \mu \mathrm{M}$. (c) P20S, p62, and alpha-synuclein Western blotting on LC3BI-II immunoprecipitates. (d) Densitometric analysis. Values are given as the optical density detected in four separate replicates $(n=4)$. Values are given as the mean number of LC $3+$ P20S puncta counted in 4 slides. Error bars represent the standard error of the mean. ${ }^{*} p \leq 0.05$ vs. control. Arrows point to P20S (red fluorescence) or LC3 (green fluorescence) or merge P20S and LC3 (orange fluorescence). Scale bar $=6.6 \mu \mathrm{m}$.

METH, P20S is already suppressed [43]. While this corresponds to a two-fold decrease in P20S-positive vacuoles (Figure 3(e)), the number of unstained METH-induced vacuoles increases by 2 -fold $([6,43]$; present study in Figure 1(b)). Remarkably, UP inhibition enhances neurotransmitter release [81, 82]; in fact, proteasome inhibitors produce striatal DA release [83]. This is due to an effect of proteasome activity in the recycling of short-lived proteins from and towards the plasma membrane including DA receptors [84], which is compatible with the retromer hypothesis for unstained vacuoles expressed above [85]. It is demonstrated that increased DA stimulation disassembles the proteasome structure, and it is related to sensitization [84]. Thus, a vicious circle may establish in which METHinduced DA release alters the proteasome structure, which in turn enhances DA release. This issue opens novel avenues to study the role of protein clearing systems in determining METH-induced sensitization. Thus, the increase in DA release occurring after $1 \mathrm{nM} \mathrm{METH}$ may be due to altered proteasome levels shown in this study. This is in line with imaging of P20S following METH compared with controls at confocal microscopy. In METH-treated cells, perimembranous rings of fluorescence appear instead of the diffuse fluorescent P20S staining occurring in controls (Figure 4(a)). 


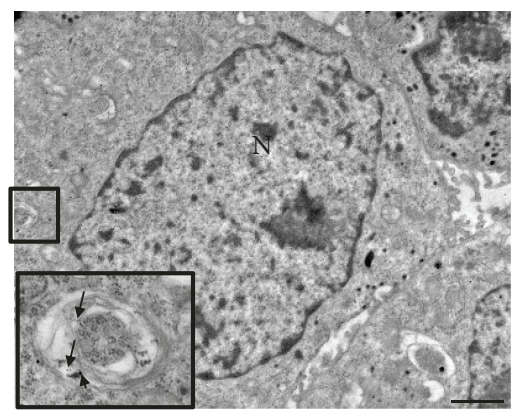

(a)

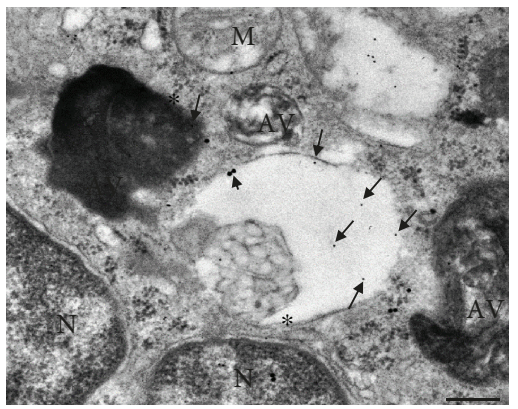

(c)

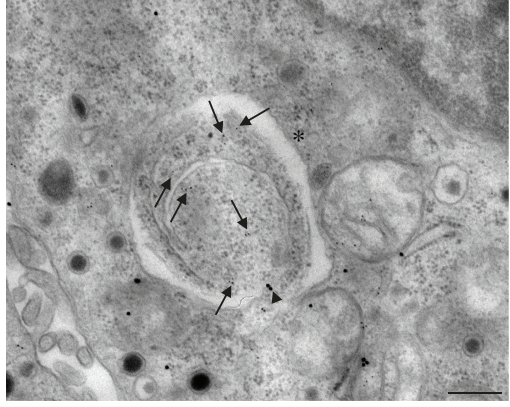

(b)

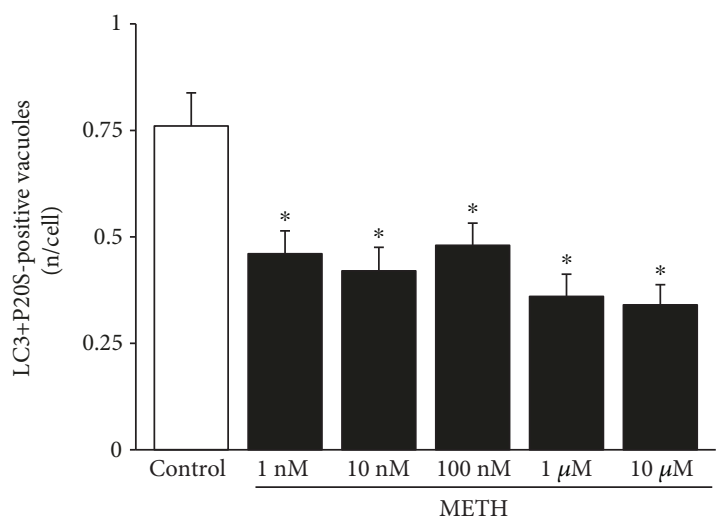

(d)

FiguRE 5: METH reduces the occurrence of autophagoproteasomes (APPs) dose-dependently. (a) Representative picture of a PC12 cell (low magnification) and an APP vacuole (high magnification). (b, c) Representative pictures of APP vacuoles stained for both LC3 (10 nm) and P20S (20 nm) immunogold particles. (d) Dose-dependent graph of the number of LC3 + P20S-positive vacuoles per cell from control and METH at $72 \mathrm{~h}$. Values are given as the mean number of LC3 + P20S-positive vacuoles counted in 100 cells per group. Error bars represent the standard error of the mean. ${ }^{*} p \leq 0.05$ vs. control. Arrows point to free LC3 particles $(10 \mathrm{~nm})$; arrowheads point to P20S particles $(20 \mathrm{~nm})$; asterisk $\left({ }^{*}\right)$ indicates a double membrane (b, c). $\mathrm{N}=$ nucleus; $\mathrm{AV}=$ autophagic vacuoles; $\mathrm{M}=$ mitochondrion. Scale bar $=220 \mathrm{~nm}$.

The discrepancy between LC3 and P20S immunogold particles extends to the time course (Supplementary Figure 1). In fact, for longer time intervals following $10 \mu \mathrm{M}$ METH, LC3 particles increase progressively (Supplementary Figure 1a), along with LC3-positive vacuoles (Supplementary Figure 1b) with a decreasing ratio between LC3 in vacuoles and LC3 in cytosol, which is time-dependent (Supplementary Figure 1c). P20S particles and vacuoles decrease slightly (Supplementary Figure 1d and Figure 1(e), respectively). The ratio between P20S in vacuoles and P20S in cytosol was similar for all time intervals (Supplementary Figure 1f). This suggests that a loss of compartmentalization for P20S is maximal already for the lowest dose of METH.

3.5. METH and Autophagoproteasome (APP). In order to document the occurrence of APP in PC12 cells and its modulation at various doses and time intervals following METH, we used confocal microscopy to document the merging between P20S and LC3 particles. As shown in representative Figure 4(a), the punctum staining for P20S and LC3 was fairly merging in baseline conditions, while only some merging could be detected also following the highest dose of METH. When we counted the amount of merging puncta detected at confocal microscopy (Figure 4(b)), these were markedly reduced following $1 \mu \mathrm{M}$ METH at each time interval $(12 \mathrm{~h}, 24 \mathrm{~h}$, and $72 \mathrm{~h})$. Confirming the hypothesis that a chemical binding between LC3 and P20S within vacuoles exists, we carried out Western blotting on LC3BI-II immunoprecipitates from whole cell lysates. In these experimental conditions, P20S was detected along with p62 (Figures 4(c) and $4(\mathrm{~d}))$. The occurrence of p62 is the key since, as recently shown by Cohen-Kaplan et al. [86], p62 is pivotal in shuttling proteasome subunits within LC3-positive autophagosomes. In line with the key role played by both ATG and proteasome to metabolize alpha-synuclein $[87,88]$, we checked whether these merging organelles contain alpha-synuclein. In fact, alpha-synuclein is detected here within immunoprecipitates (Figures 4(c) and 4(d)). Incidentally, these findings indicate why, in biochemical studies, the metabolism of alphasynuclein was attributed to ATG, UP, or both, depending on the study [89-91]. The present research paper demonstrates at the morphological level the occurrence of a single organelle hosting both UP and ATG components, which recruits alpha-synuclein (Figure 4(c)). When analyzed at ultrastuctural morphometry, these merging units between P20S and LC3 appear as vacuoles owning different shapes and structures corresponding to autophagoproteasomes (APPs, Figures 4(a), 5(b), and 5(c)). It is remarkable that, 


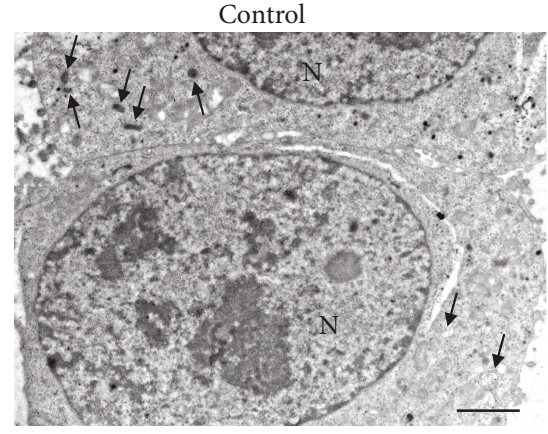

(a)

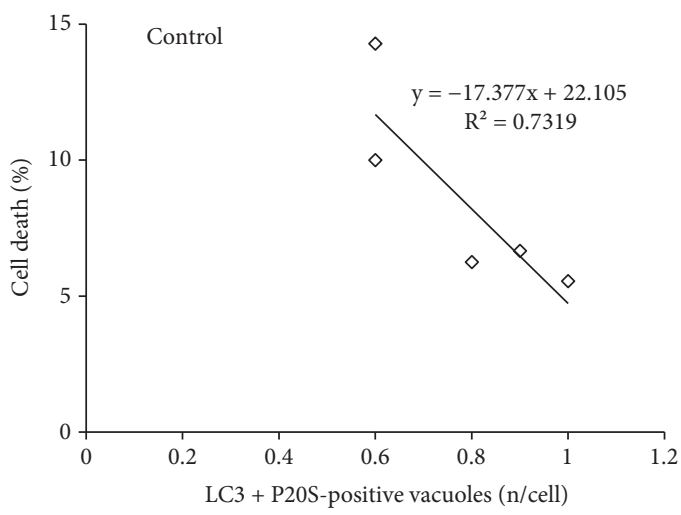

(c)

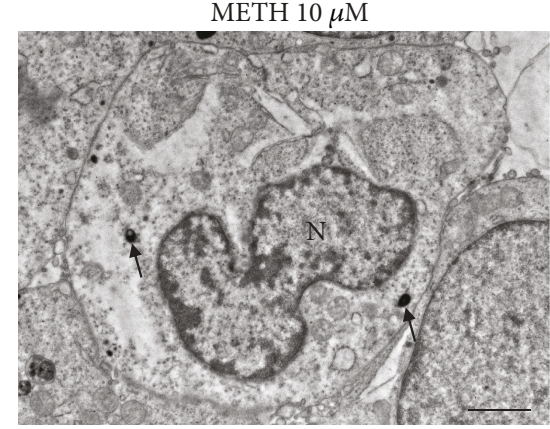

(b)

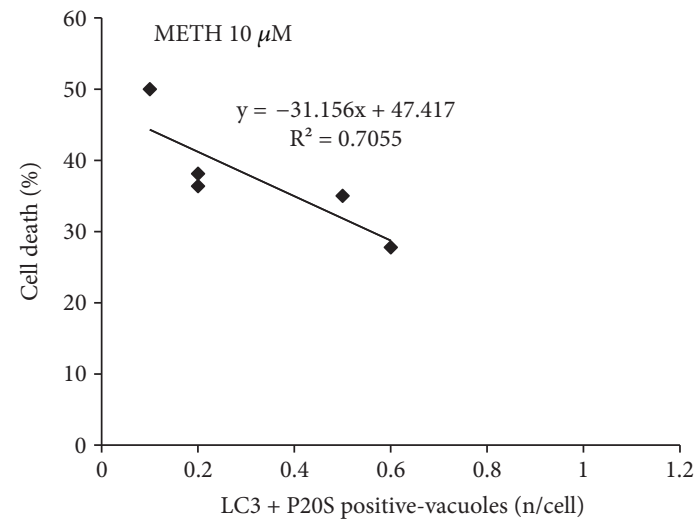

(d)

FIGURE 6: Inverse correlation between the occurrence of APP and METH-induced toxicity. (a) Representative micrograph from a control cell. (b) Representative micrograph from a cell following METH at $72 \mathrm{~h}$. (c) Linear regression between the percentage of cell death and the number of LC3 + P20S-positive vacuoles in control. (d) Linear regression between the percentage of cell death and the number of LC3 + P20S-positive vacuoles following METH at $72 \mathrm{~h}$. The puncta reported in the graphs ((c) white square and (d) black square) correspond to the number of grid $(n=5)$. Arrows point to vacuoles. $\mathrm{N}=$ nucleus. Scale bar $=1 \mu \mathrm{m}$.

according to confocal microscopy, under METH administration, a marked suppression was counted for APP for each dose of $\mathrm{METH}$ ranging between $1 \mathrm{nM}$ and $10 \mu \mathrm{M}$ as shown in the graph of Figure 5(d). Similarly, just like it was described for the time course detected at confocal microscopy, even at TEM, APP was similarly depressed by METH at 12, 24, and $72 \mathrm{~h}$ (Supplementary Figure 2). The number of APP in controls (representative Figure 6(a)) and following METH (Figure 6(b)) was plotted for a regression analysis between the amount of APPs and the number of dead cells in controls (graph of Figure 6(c)) and following METH (graph of Figure 6(d)). A negative correlation was detected between cell death and the number of APPs with a slope, which was consistent in control conditions and following METH at $10 \mu \mathrm{M}$. In fact, in both experimental conditions, cell death was lesser and lesser when APPs were more and more expressed. In controls, dead cells exceeded $10 \%$ in those samples owning only a few APPs/cell (roughly 0.6), while cell death was occluded down to $5 \%$ when APPs increased two-fold (graph of Figure 6(c)). As expected, the percentage of cell death reached almost $50 \%$ following the $10 \mu \mathrm{M}$ dose of METH, when only a few APPs were produced (roughly 0.1 per cell); in contrast, cell death was toned down to $30 \%$ in those samples in which the amount of APPs was six-fold higher (roughly 0.6 per cell, graph of Figure 6(d)).
3.6. The Effects of mTOR Modulation on P20S, LC3, and Autophagoproteasome Related with METH Neurotoxicity. As previously published, mTOR activity finely tunes APP [47]. Therefore, in order to test in the present experiments the effects of specific doses of compounds, which are known to act either as mTOR inhibitors or activators, we measured the amount of the downstream product of mTOR activity (pS6). Asparagine is a well-known mTORC1 activator [92] while rapamycin is the gold standard mTORC1 inhibitor $[93,94]$. The doses of these compounds were tested as reported in Figure 7. Asparagine at the dose of $50 \mathrm{mM}$ activates $\mathrm{mTOR}$ while rapamycin at the dose of $100 \mathrm{nM}$ inhibits mTOR as calculated by the amount of Western blotted pS6. Therefore, owning the right compounds at appropriated doses, we tested the effects of these compounds on cell death and amount of APPs. As shown in representative micrographs of Figure 8, we observed a variety of effects, which are in line with the key role of $\mathrm{mTOR}$ in METH toxicity and APP stimulation [80, 94, 95]. In fact, the dose of $10 \mu \mathrm{M}$ METH produces roughly 35\% cell death, which was totally prevented by rapamycin $(100 \mathrm{nM})$. Remarkably, rapamycin alone further reduced cell death significantly below levels found in control cells. This witnesses for the presence of a baseline inherent aberrancy of mTOR regulation in this cell line, which is reminiscent of neurodegeneration [49]. 


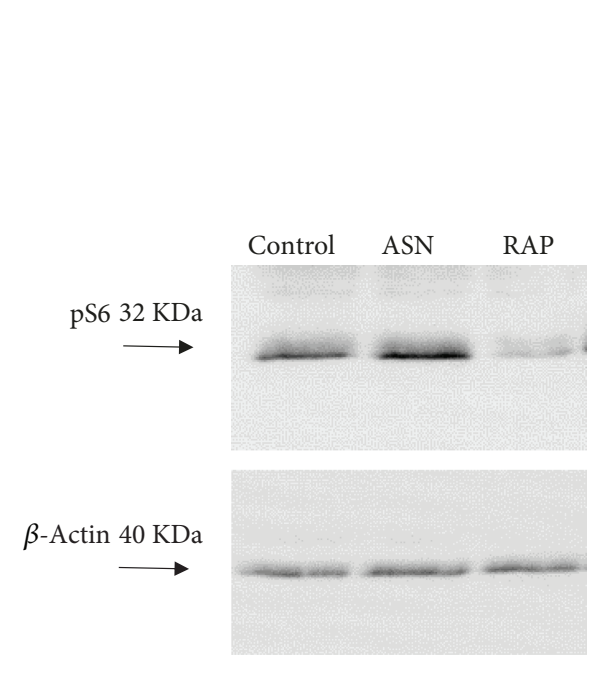

(a)

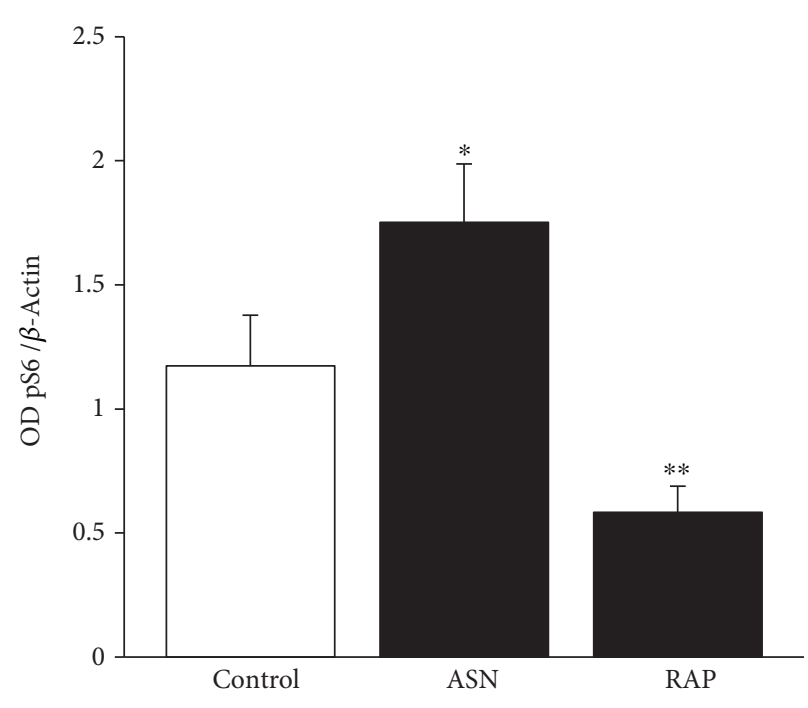

(b)

FIGURE 7: Modulation of pS6 levels underlie mTOR inhibition and activation by rapamycin and asparagine, respectively. (a) Representative SDS-PAGE immunoblotting of pS6 protein. (d) Densitometric analysis. Values are given as the optical density detected in six separate replicates $(n=6)$. Error bars represent the standard error of the mean. ${ }^{*} p \leq 0.05$ vs. control; ${ }^{* *} p \leq 0.05$ vs. control and METH. $\mathrm{ASN}=$ asparagine; $\mathrm{RAP}=$ rapamycin .

Incidentally, this is the first report showing that the gold standard inhibitor of mTOR rapamycin prevents METH toxicity. This key finding provided here as side observation is in need of a dedicated experimental project. So far, only taurine and melatonin were shown to slightly prevent METH toxicity with an indirect evidence of mTOR-mediated mechanisms $[94,96]$, although this was interpreted using a multifaceted hypothesis. Remarkably, recent evidence, despite not addressing directly METH neurotoxicity, demonstrated that METH-induced behavioral sensitization associates with mTOR overexpression, while rapamycin reverts such an effect [97]. Again, the stimulation of DA D1 receptors, which are key in both METH-induced toxicity and behavioral sensitization $[9,98]$, directly promotes mTOR activation while inhibiting autophagy [99].

The present study directly relates neuroprotection with mTOR inhibition, while showing that METH impairs autophagy. This was consolidated by the deleterious effects of asparagine. In fact, in the graph of Figure 8(b), we found that asparagine alone was slightly increasing the natural cell death occurring in control cells but it did not really increase much the amount of METH-induced cell death. When all the three compounds were coadministered, the protective effects of rapamycin prevailed, with a robust suppression of cell death occurring following METH + asparagine (graph of Figure 8). These data concerning cell death were almost mirrored by each treatment in the count of APPs. In detail, METH suppressed APPs while rapamycin increased their number almost two-fold of controls. Asparagine, as expected, depressed APPs similarly to METH, while the combination METH + asparagine produced the lowest number of APPs (3-fold less than controls). It is remarkable that rapamycin rescued the loss of APPs induced following either asparagine alone or asparagine $+\mathrm{METH}$
(Figure 8(c)). This strengthens the significance of the present data concerning the role of mTOR in tuning METH toxicity and APPs in a reciprocal pattern.

Here, we wish to emphasize the protective effects of $\mathrm{mTOR}$ inhibition on natural cell death which occurs in the PC12 cell line. In fact, these cells possess an inherent aberrancy, which is useful in understanding neuronal degeneration [49]. This is partly due to an aberrancy in DA compartmentalization and vesicle polarization, where in baseline conditions most neurotransmitter is docking to the cell membrane, making this cell line highly prone to produce massive amount of self-oxidized DA metabolites [49]. It is remarkable that upgrading APPs through mTOR inhibition erases such an inborn trend to degenerate. Since UP inhibition enhances DA release, which is related to METH toxicity, it is expected that mTOR activation, by inhibiting UP activity and compartmentalization, enhances METH-induced cell death. The present research seems to uncover the molecular determinants of inherent vulnerability of the DA-PC12 cell line, by targeting specifically mTORC1 complex dysregulation.

3.7. The Effects of mTOR Modulation on Unstained Vacuoles. When these experimental conditions were applied to unstained vacuoles (representative picture of Supplementary Figure 3), data obtained were quite similar to APPs, though with some exceptions. In fact, METH increases the number of unstained vacuoles, which were further increased by rapamycin alone, way more compared with LC3-positive vacuoles (roughly 20 per cell and roughly 8 per cell, respectively). This adds further information about the previous question concerning the nature of these unstained vacuoles, which turn out to be mTOR-dependent. Unexpectedly, combined administration of METH and rapamycin instead of further increasing the number of 


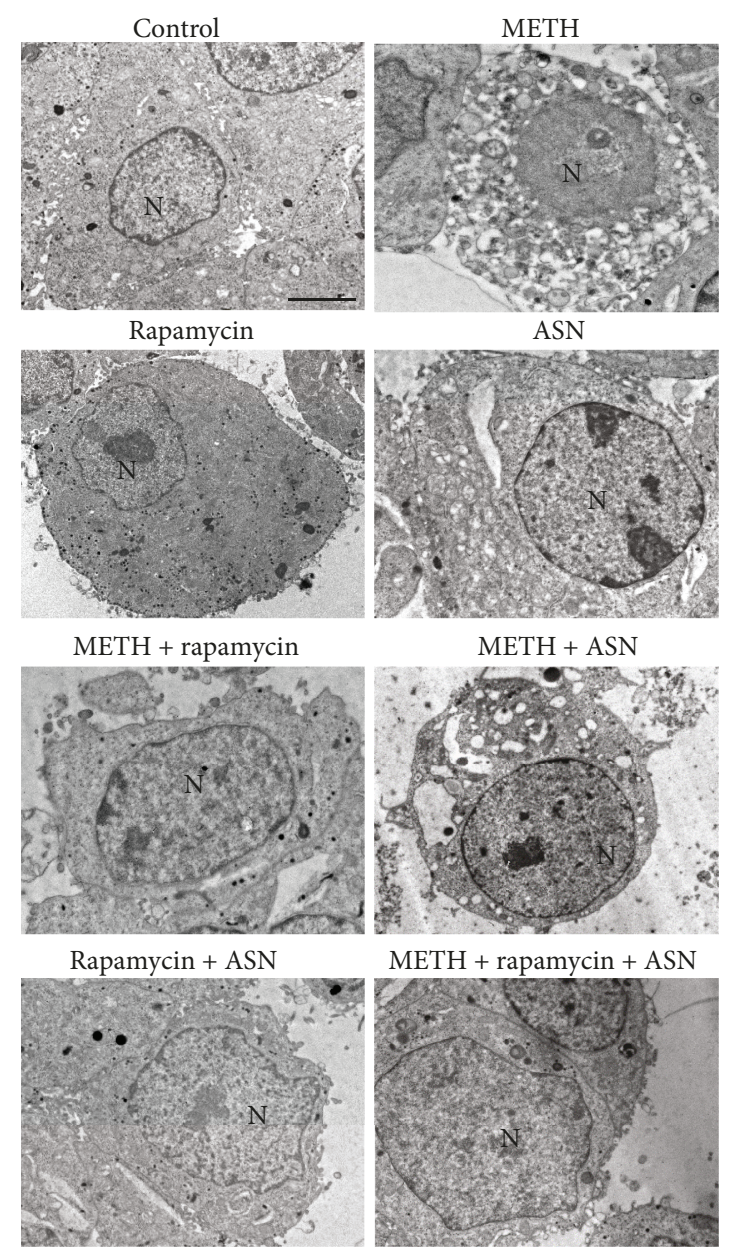

(a)

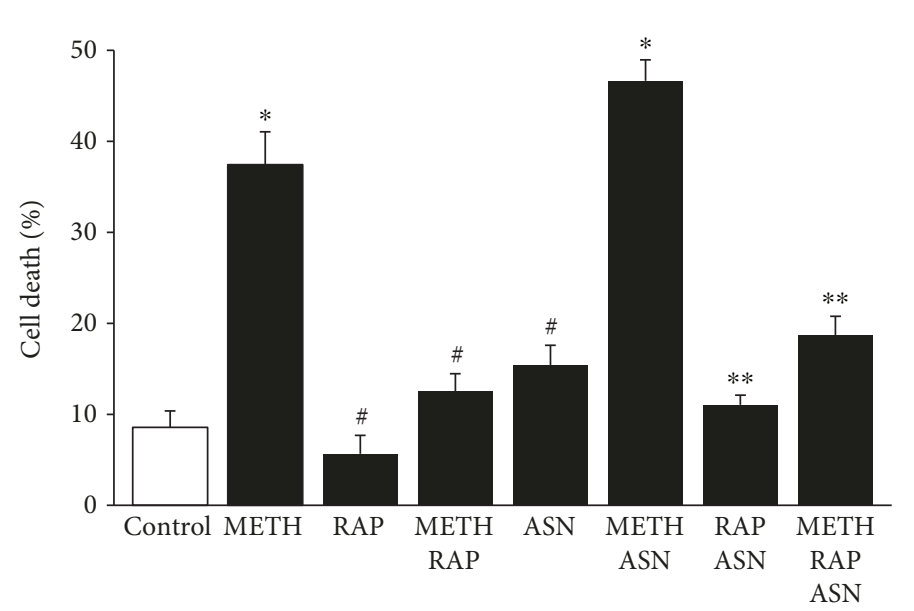

(b)

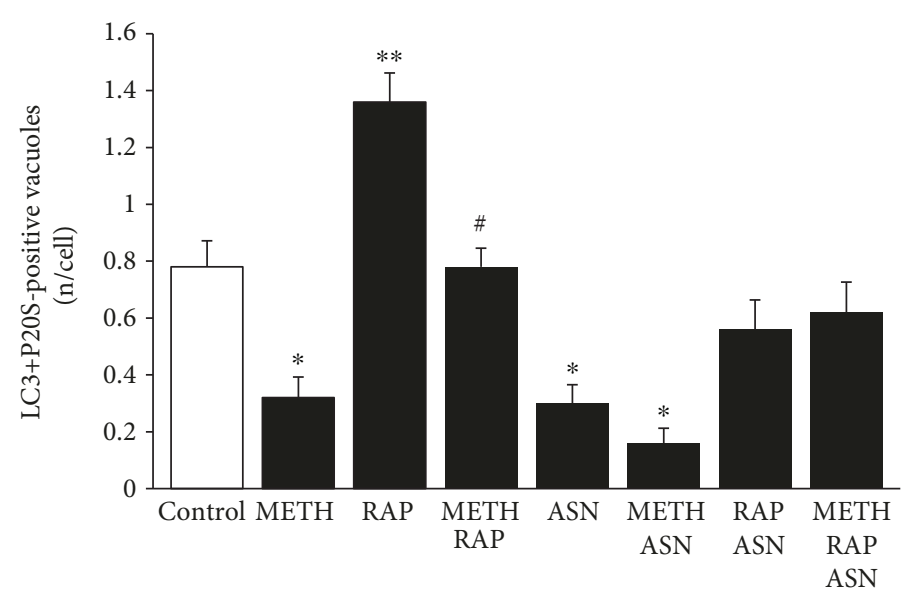

(c)

FIGURE 8: mTOR inhibition prevents cell death and rescues the amount of APPs induced by METH and the mTOR activator asparagine. (a) Representative micrographs of control and following METH $10 \mu \mathrm{M}$, rapamycin $100 \mathrm{nM}$, and asparagine $50 \mathrm{mM}$, at $72 \mathrm{~h}$. (b) Graph of the percentage of cell death in control and following METH $10 \mu \mathrm{M}$, rapamycin $100 \mathrm{nM}$, and asparagine $50 \mathrm{mM}$, at $72 \mathrm{~h}$. (c) Graph of the number of LC3 + P20S-positive vacuoles in control and following METH $10 \mu \mathrm{M}$, rapamycin $100 \mathrm{nM}$, and asparagine $50 \mathrm{mM}$, at $72 \mathrm{~h}$. For the graph in (b), values are given as the percentage of cell counted on 5 grids. For the graph in (c), values are given as the mean number of LC3 + P20S-positive vacuoles counted in 100 cells per group. Error bars represent the standard error of the mean. ${ }^{*} p \leq 0.05$ vs. control; ${ }^{* *} p \leq 0.05$ vs. control and METH; ${ }^{\#} p \leq 0.05$ vs. METH. $\mathrm{N}=$ nucleus; $\mathrm{ASN}=$ asparagine; $\mathrm{RAP}=$ rapamycin. Scale bar $=0.5 \mu \mathrm{m}$.

unstained vacuoles compared with rapamycin alone produces a decrease in these vacuoles (which remain higher than controls). It is likely that, in the presence of rapamycin, there is no longer an oxidative stress, which produces an altered vesicle trafficking. In fact, mTOR inhibition stimulates both the activity and the amount of the proteasome subunit, which suppresses DA release. Thus, according to the hypothesis that unstained vacuoles are due to DA release and proteasome dysfunction mutually enhancing each other, it is expected that rapamycin occludes this component. Thus, combined METH and rapamycin administration produces a number of unstained vacuoles which is still higher than controls but lower than rapamycin alone. Asparagine alone or in combination with METH decreased unstained vacuoles, which were brought up to control the levels by adding rapamycin (Supplementary Figure 3).
These data suggest that the mechanisms by which unstained vacuoles are increased are different following rapamycin compared with METH administration, since double treatment occludes this effect instead of enhancing it. This is consistent with the opposite effects on cell death, which is induced by METH and rescued by rapamycin. In contrast, APP vacuoles despite being decreased by METH were increased by rapamycin, which witnesses for a different regulation of unstained compared with APP vacuoles.

3.8. The Effects of mTOR Modulation on LC3. Following mTOR inhibition by rapamycin, LC3 particles were never depressed below control values, even when METH and asparagine were combined. In these experimental conditions, compartmentalization of LC3 particles within vacuoles was dramatically enhanced by rapamycin. This mechanism was 


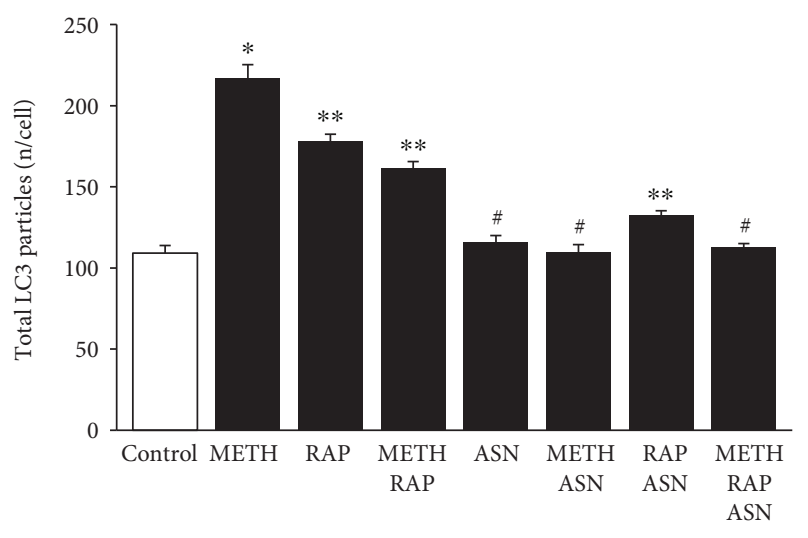

(a)

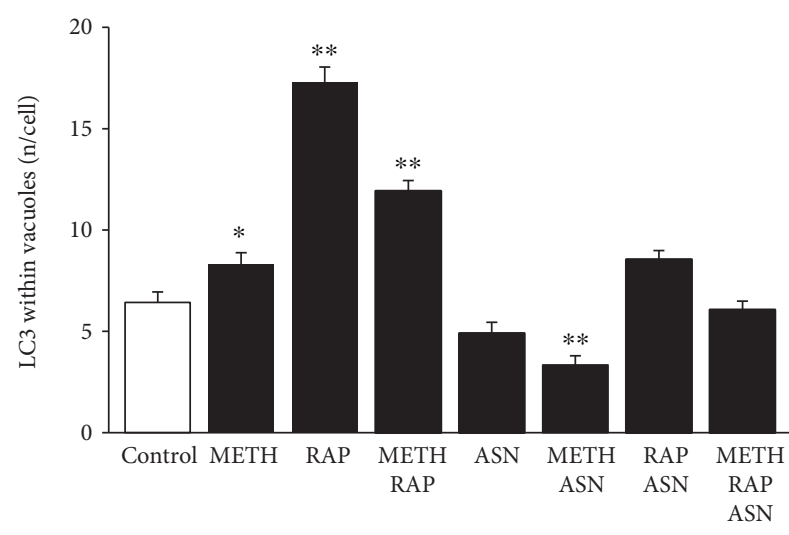

(c)

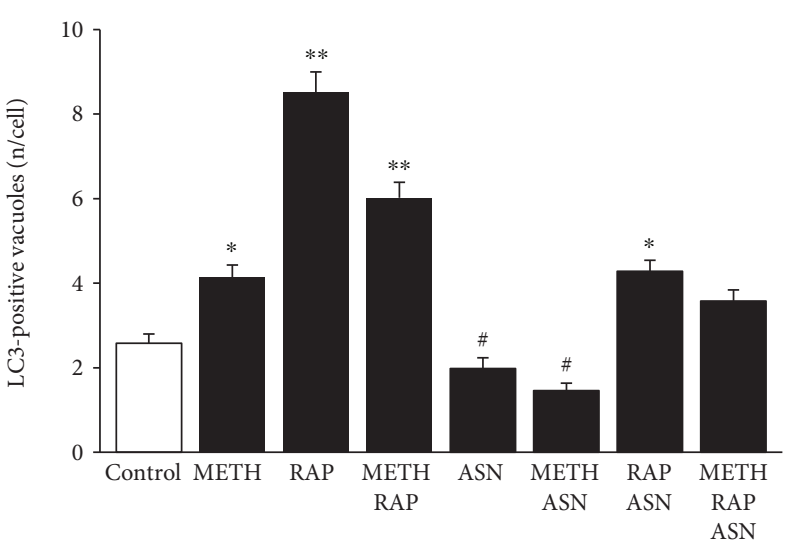

(b)

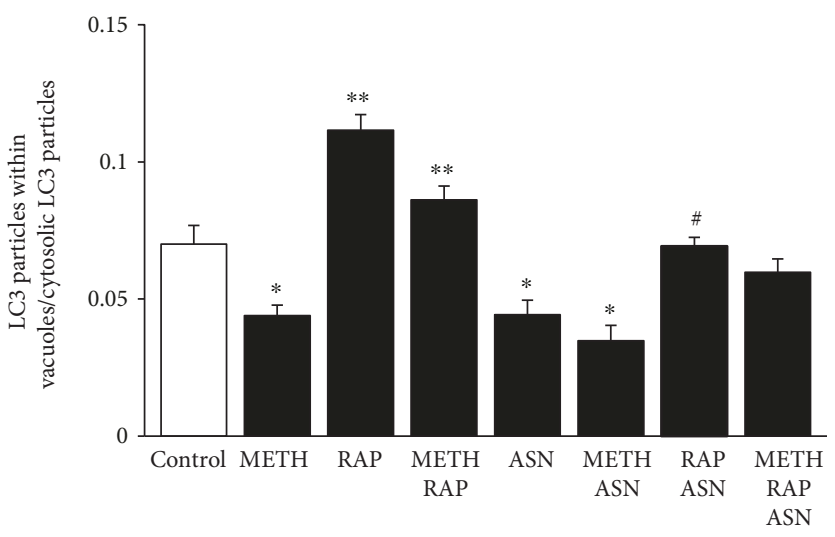

(d)

FIGURE 9: mTOR modulates the number and placement of LC3 particles. (a) The graph shows the number of total LC3 particles per cell in control, following METH $10 \mu \mathrm{M}$, rapamycin $100 \mathrm{nM}$, and asparagine $50 \mathrm{mM}$, at $72 \mathrm{~h}$. (b) The graph shows the number of LC3-positive vacuoles per cell in control, following METH $10 \mu \mathrm{M}$, rapamycin $100 \mathrm{nM}$, and asparagine $50 \mathrm{mM}$, at $72 \mathrm{~h}$. (c) The graph shows the number of LC3-positive vacuoles in control and following METH $10 \mu \mathrm{M}$, rapamycin $100 \mathrm{nM}$, and asparagine $50 \mathrm{mM}$, at $72 \mathrm{~h}$. (d) The graph shows the ratio between the number of LC3 particles within vacuoles and cytosolic LC3 particles. Values are given as the mean number of LC3 particles and vacuoles counted in 50 cells per group. Error bars represent the standard error of the mean. ${ }^{*} p \leq 0.05$ vs. control; ${ }^{* *} p \leq 0.05$ vs. control and METH; ${ }^{\#} p \leq 0.05$ vs. METH.

independent from the one produced by $\mathrm{METH}$; in fact, despite METH $10 \mu \mathrm{M}$ was more effective than rapamycin $100 \mathrm{nM}$ to increase total LC3 particles in the cell, rapamycin alone was much more powerful than METH alone in increasing LC3 within vacuoles (Figure 9(a)). Again, when rapamycin was combined with METH, a decrease of vacuolar LC3 was detected compared with rapamycin alone (Figure 9(b)). This indicates a strong compartmentalizing effect of rapamycin, which sharply contrasts with METH-induced LC3 dispersion (the generalized and nonspecific increase of LC3 promoted by METH, Figure 9(a)). The mTOR activator asparagine alone or in combination with METH further dispersed LC3 particles, since it decreased the placement of LC3 within vacuoles. This witnesses for a strong modulation by mTOR of LC3 compartmentalization (Figure 9(c)). This was further evidenced by counting the number of LC3 particles in the vacuoles versus LC3 particles within the cytosol (Figure 9(d)). In this case, METH decreases the ratio compared with controls, while rapamycin was increasing two-fold the ratio compared with controls and reverted the effects of METH. Asparagine alone was similar to METH and further suppressed the ratio when it was combined with METH.

3.9. The Effects of mTOR Modulation on P20S. The effects of mTOR inhibition were sharply contrasting with the effects of METH concerning the amount and placement of P20S particles. In fact, while METH depressed, rapamycin increased total P20S (Figure 10(a)). Moreover, rapamycin reverted the suppression induced by METH, while the effect of asparagine alone was less effective compared with METH. Combined administration of asparagine and METH did not alter the effects produced by METH alone. The effects of asparagine were antagonized by rapamycin. This was replicated by the number of P20S in the vacuoles (Figures 10(b) and 10(c)). When counting P20S-positive vacuoles or P20S in the vacuoles (Figures 10(b) and $10(\mathrm{c})$, respectively), although the general trend was similar to what is described in Figure 10(a), there was a remarkable difference concerning asparagine. In fact, the polarization of P20S within vacuoles was dramatically suppressed 


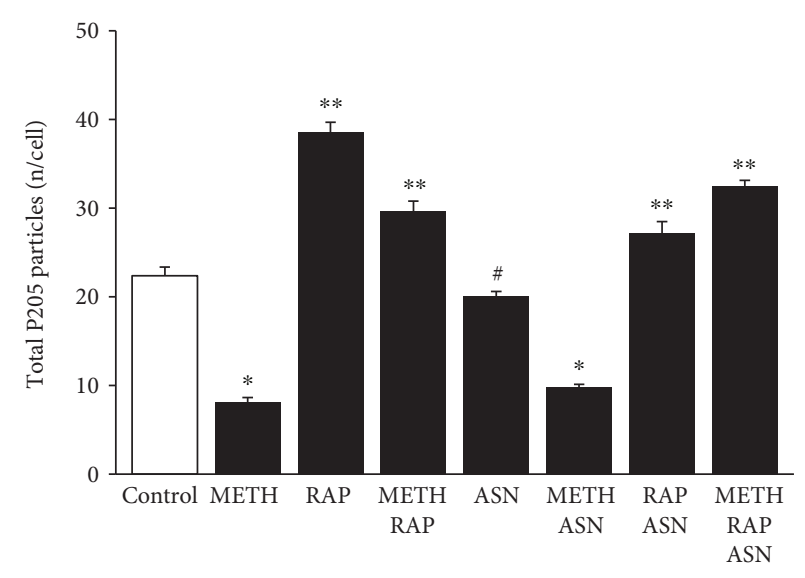

(a)

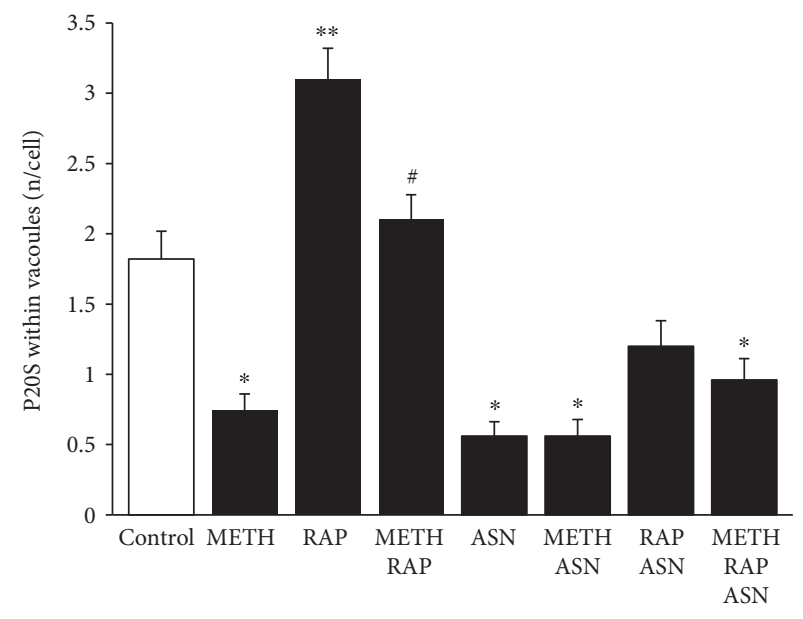

(c)

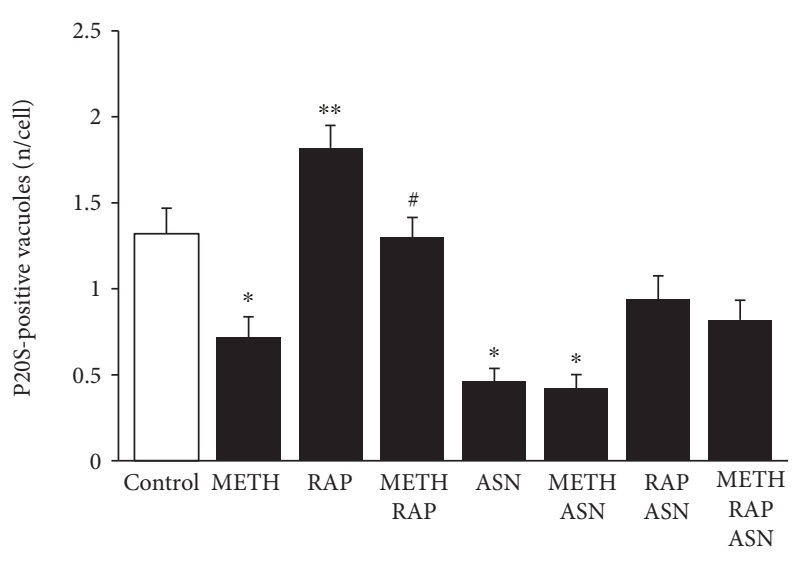

(b)

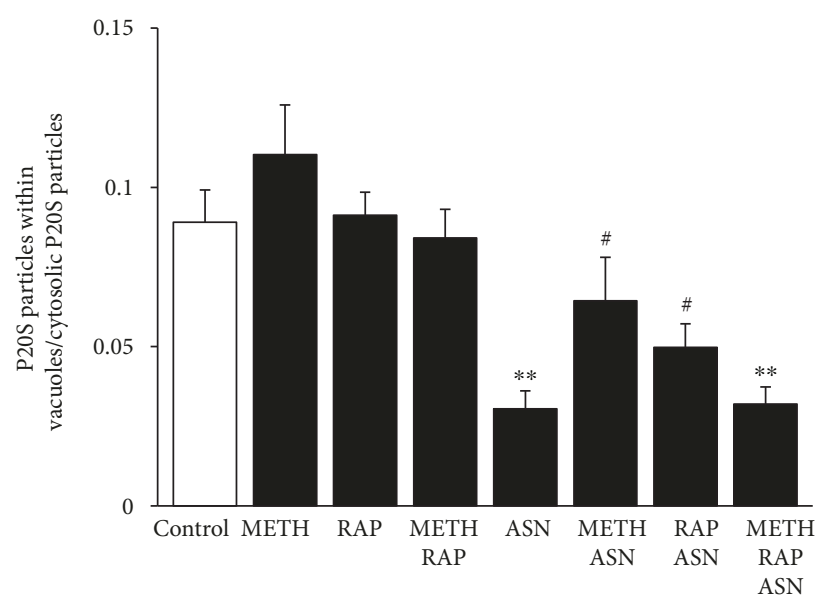

(d)

FIgURE 10: mTOR modulates the number and placement of P20S particles. (a) The graph shows the number of total P20S particles per cell in control, following METH $10 \mu \mathrm{M}$, rapamycin $100 \mathrm{nM}$, and asparagine $50 \mathrm{mM}$, at $72 \mathrm{~h}$. (b) The graph shows the number of P20S-positive vacuoles per cell in control, following METH $10 \mu \mathrm{M}$, rapamycin $100 \mathrm{nM}$, and asparagine $50 \mathrm{mM}$, at $72 \mathrm{~h}$. (c) The graph shows the number of P20S-positive vacuoles in control and following METH $10 \mu \mathrm{M}$, rapamycin $100 \mathrm{nM}$, and asparagine $50 \mathrm{mM}$, at $72 \mathrm{~h}$. (d) The graph shows the ratio between the number of P20S particles within vacuoles and cytosolic P20S particles. Values are given as the mean number of P20S particles and vacuoles counted in 50 cells per group. Error bars represent the standard error of the mean. ${ }^{*} p \leq 0.05$ vs. control; ${ }^{* *}$ $p \leq 0.05$ vs. control and METH; ${ }^{\#} p \leq 0.05$ vs. METH. ASN = asparagine; RAP = rapamycin.

by this mTOR activator even when compared with METH. Moreover, the effects of asparagine on the dispersion of P20S was so powerful that even rapamycin was not able to prevent it (Figure 10(d)).

3.10. Correlation between Autophagoproteasomes and Cell Death. The effects of all these treatments on the amount of APPs versus the occurrence of cell death were plotted in the graph of Figure 11, which remarks for various mTOR modulators and a powerful negative correlation between the number of APPs and the number of dead cells.

In conclusions, the negative correlation which was described for APP and cell death in controls and following a $10 \mu \mathrm{M}$ dose of METH (Figure 6) was strengthened by the analysis carried out with mTOR modulators (Figure 8). This final plotting shows, at one glance, how mTOR inhibition is key for producing the merging between proteasome and autophagy to build autophagoproteasome, while it is compatible with a strong neuroprotective role exerted by such a merging organelle.

\section{Concluding Remarks}

METH administration is known to increase the number of ATG vacuoles within catecholamine-containing cells. This was originally published by Cubells et al. [22], and at first, it was suggested to produce ATG-mediated cell damage [22].

Nonetheless, in 2008, we demonstrated that the inhibition of ATG in METH-treated catecholamine cells instead of producing neuroprotection worsened METH neurotoxicity indicating a compensatory neuroprotection for ATG induction during $\mathrm{METH}$ toxicity, as confirmed by several studies [16, 37, 80, 100-102].

In line with this, in the present manuscript, we demonstrate that rapamycin administration fully rescues 


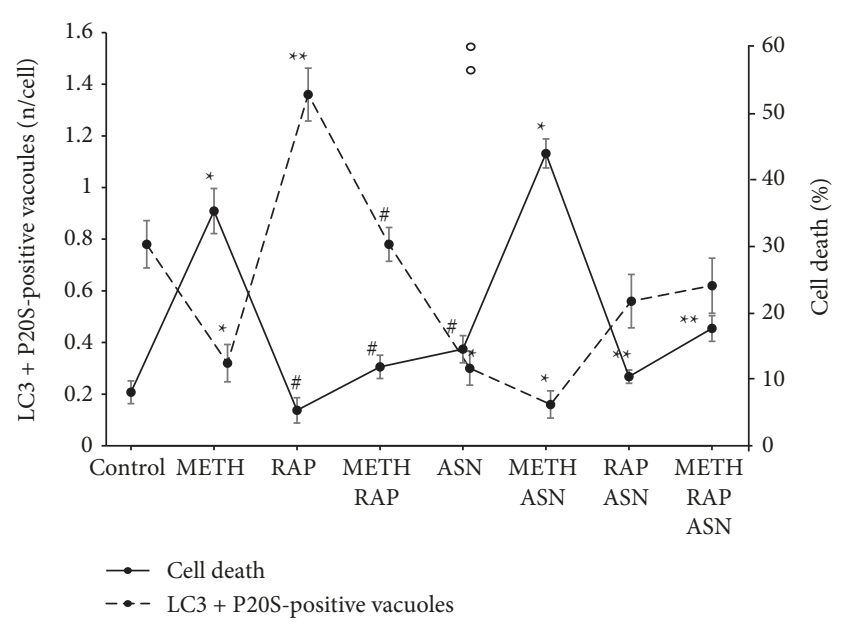

FIGURE 11: Inverse correlation between cell death and amount of APPs following mTOR modulation. The dashed line shows the amount of APPs while the continuous line shows the percentage of cell death. For each treatment, the values of the two lines produce a mirror image, which indicates a negative correlation. ${ }^{*} p \leq 0.05$ vs. control; ${ }^{* *} p \leq 0.05$ vs. control and METH; ${ }^{*} p \leq$ 0.05 vs. $\mathrm{METH}$. $\mathrm{ASN}=$ asparagine; $\mathrm{RAP}=$ rapamycin.

METH-induced cell death. In the present paper, apart from strengthening the concept that mTOR inhibition and ATG protect against METH toxicity, we further detail the significance of specific ATG-related structures.

It is believed that METH-induced increase in LC3 immunofluorescence is produced by an increase in LC3positive stagnant ATG vacuoles with an impairment of the autophagy flux [37]. However, in the present study, we demonstrate that, under METH administration, there is a loss of compartmentalization of LC3 particles within vacuoles. In fact, LC3 particles increase more in the cytosol than within vacuoles, which represents a novel insight in ATG and METH toxicity.

This leads to reconsider the significance of densely fluorescent LC3 spots detected at confocal microscopy following $\mathrm{METH}$, since the greatest contribution is provided by free cytosolic LC3.

In these experimental conditions, the effects of rapamycin are demonstrated to be neuroprotective against cell death while reinstating vacuolar compartmentalization of both LC3 and P20S.

It is likely that a concomitant acceleration of activity within stagnant ATG vacuoles may concur to provide neuroprotection. In fact, asparagine, which also impairs the merge between autophagosomes and lysosomes, produces a dramatic effect.

In these experimental conditions, the occurrence of ATG vacuoles is further dissected for the concomitant presence of the P20S proteasome component. It is now well established that these LC3 + P20S vacuoles contain both ATG and proteasome markers and are named "autophagoproteasomes" (APPs) [48].

In the present study, we demonstrate that LC3 + P20Spositive vacuoles (APP) represents a clearing compartment which behaves distinctly and sometimes opposite to classic ATG (LC3-positive) compartment. This specific compartment correlates with cell survival. In line with this, alphasynuclein, which is known to buffer oxidative species [103, 104], is involved in METH toxicity, since in alphasynuclein knockout mice, a potentiation of METH-induced nigrostriatal damage occurs [105]. The coimmunoprecipitation of alpha-synuclein within APPs found here corroborates such a neuroprotective effect. This novel organelle may counteract also impaired mitophagy during METH administration. In fact, few key steps in mitochondrial removal are carried out by proteasome components acting during early autophagosome formation $[39,106,107]$.

As a proof of principle, we cannot be satisfied yet, since one might argue that a defect in ATG progression may lead ATG vacuoles not to be able to take up the proteasome component due to a failure in the p62-driven uptake of ubiquitinated proteasomes. When such an alternative explanation is consistent, then an increased amount of P20S should be measured in the cytosol. However, the number of P20S in the cytosol was decreased by METH administration, and it was further suppressed by the concomitant administration of asparagine.

Again, if the decreased amount of UP within ATG vacuoles were related to a decrease of ATG progression (impaired shuttling of P20S within ATG vacuoles), the ratio between cytosolic vs. vacuolar P20S should be modified by METH, while this ratio stays steady.

\section{Data Availability}

The data used to support the findings of this study are available from the corresponding author upon request.

\section{Conflicts of Interest}

The authors declare that there is no conflict of interest regarding the publication of this paper.

\section{Authors' Contributions}

Gloria Lazzeri and Francesca Biagioni equally contributed to the present manuscript.

\section{Acknowledgments}

We are grateful to Dr. Marina Flaibani for the precious technical support. This work was supported by Ricerca Corrente 2018 (Ministero della Salute).

\section{Supplementary Materials}

Supplementary Figures 1, 2, and 3: further evidence about various METH-induced ultrastructural alterations. In all these graphs, the dose of METH was kept constant $10 \mu \mathrm{M}$. Supplementary Figure 1: the time dependency of METHinduced variations in LC3 and P20S particles $(12 \mathrm{~h}, 24 \mathrm{~h}$, and $72 \mathrm{~h}$ ). Counts refer to whole cytosol or selectively within vacuoles. Moreover, the ratio between compartmentalized particles within vacuoles and total cytosolic particles at these 
time intervals is reported. Supplementary Figure 2: the time dependency of METH-induced suppression of APPs, which concerns selectively with the number of LC3 + P20S-positive vacuoles (autophagoproteasomes) in the whole cytosol. Supplementary Figure 3: the number of unstained vacuoles in the whole cytosol following various single and combined treatments with mTOR modulators. (Supplementary Materials)

\section{References}

[1] N. D. Volkow, L. Chang, G. J. Wang et al., “Association of dopamine transporter reduction with psychomotor impairment in methamphetamine abusers," American Journal of Psychiatry, vol. 158, no. 3, pp. 377-382, 2001.

[2] D. E. Rusyniak, "Neurologic manifestations of chronic methamphetamine abuse," Neurologic Clinics, vol. 29, no. 3, pp. 641-655, 2011.

[3] G. C. Wagner, G. A. Ricaurte, L. S. Seiden, C. R. Schuster, R. J. Miller, and J. Westley, "Long-lasting depletions of striatal dopamine and loss of dopamine uptake sites following repeated administration of methamphetamine," Brain Research, vol. 181, no. 1, pp. 151-160, 1980.

[4] G. A. Ricaurte, R. W. Guillery, and L. S. Seiden, "Dopamine nerve terminal degeneration produced by high doses of methylamphetamine in the rat brain," Brain Research, vol. 235, no. 1, pp. 93-103, 1982.

[5] J. M. Wilson, K. S. Kalasinsky, A. I. Levey et al., "Striatal dopamine nerve terminal markers in human, chronic methamphetamine users," Nature Medicine, vol. 2, no. 6, pp. 699-703, 1996.

[6] F. Fornai, P. Lenzi, M. Gesi et al., "Methamphetamine produces neuronal inclusions in the nigrostriatal system and in PC12 cells," Journal of Neurochemistry, vol. 88, no. 1, pp. 114-123, 2004.

[7] B. Liu and D. E. Dluzen, "Effect of estrogen upon methamphetamine-induced neurotoxicity within the impaired nigrostriatal dopaminergic system," Synapse, vol. 60, no. 5, pp. 354-361, 2006.

[8] S. Ares-Santos, N. Granado, I. Espadas, R. Martinez-Murillo, and R. Moratalla, "Methamphetamine causes degeneration of dopamine cell bodies and terminals of the nigrostriatal pathway evidenced by silver staining," Neuropsychopharmacology, vol. 39, no. 5, pp. 1066-1080, 2014.

[9] S. Ares-Santos, N. Granado, I. Oliva et al., "Dopamine $\mathrm{D}(1)$ receptor deletion strongly reduces neurotoxic effects of methamphetamine," Neurobiology of Disease, vol. 45, no. 2, pp. 810-820, 2012.

[10] N. Granado, S. Ares-Santos, E. O’Shea, C. Vicario-Abejón, M. I. Colado, and R. Moratalla, "Selective vulnerability in striosomes and in the nigrostriatal dopaminergic pathway after methamphetamine administration: early loss of $\mathrm{TH}$ in striosomes after methamphetamine," Neurotoxicity Research, vol. 18, no. 1, pp. 48-58, 2010.

[11] N. Granado, S. Ares-Santos, and R. Moratalla, "D1 but not D4 dopamine receptors are critical for MDMA-induced neurotoxicity in mice," Neurotoxicity Research, vol. 25, no. 1, pp. 100-109, 2014.

[12] N. Granado, S. Ares-Santos, Y. Tizabi, and R. Moratalla, "Striatal reinnervation process after acute methamphetamine-induced dopaminergic degeneration in mice," Neurotoxicity Research, vol. 34 , no. 3, pp. 627-639, 2018.
[13] F. Fornai, P. Lenzi, M. Gesi et al., "Similarities between methamphetamine toxicity and proteasome inhibition," Annals of the New York Academy of Sciences, vol. 1025, no. 1, pp. 162-170, 2004.

[14] F. Fornai, G. Lazzeri, A. Bandettini Di Poggio et al., "Convergent roles of $\alpha$-synuclein, DA metabolism, and the ubiquitin-proteasome system in nigrostriatal toxicity," Annals of the New York Academy of Sciences, vol. 1074, no. 1, pp. 84-89, 2006.

[15] G. Lazzeri, P. Lenzi, C. L. Busceti et al., "Mechanisms involved in the formation of dopamine-induced intracellular bodies within striatal neurons," Journal of Neurochemistry, vol. 101, no. 5, pp. 1414-1427, 2007.

[16] M. Lin, P. Chandramani-Shivalingappa, H. Jin et al., "Methamphetamine-induced neurotoxicity linked to ubiquitin-proteasome system dysfunction and autophagyrelated changes that can be modulated by protein kinase C delta in dopaminergic neuronal cells," Neuroscience, vol. 210, pp. 308-332, 2012.

[17] L. Quan, T. Ishikawa, T. Michiue et al., "Ubiquitin-immunoreactive structures in the midbrain of methamphetamine abusers," Legal Medicine, vol. 7, no. 3, pp. 144-150, 2005.

[18] P. K. Sonsalla, J. W. Gibb, and G. R. Hanson, "Roles of D1 and D2 dopamine receptor subtypes in mediating the methamphetamine-induced changes in monoamine systems," Journal of Pharmacology and Experimental Therapeutics, vol. 238, no. 3, pp. 932-937, 1986.

[19] J. W. Gibb, M. Johnson, and G. R. Hanson, "Neurochemical basis of neurotoxicity," Neurotoxicology, vol. 11, no. 2, pp. 317-321, 1990.

[20] D. Sulzer and S. Rayport, "Amphetamine and other psychostimulants reduce $\mathrm{pH}$ gradients in midbrain dopaminergic neurons and chromaffin granules: a mechanism of action," Neuron, vol. 5, no. 6, pp. 797-808, 1990.

[21] D. Sulzer, E. Pothos, H. M. Sung, N. T. Maidment, B. G. Hoebel, and S. Rayport, "Weak base model of amphetamine action," Annals of the New York Academy of Sciences, vol. 654, no. 1, pp. 525-528, 1992.

[22] J. F. Cubells, S. Rayport, G. Rajendran, and D. Sulzer, "Methamphetamine neurotoxicity involves vacuolation of endocytic organelles and dopamine-dependent intracellular oxidative stress," Journal of Neuroscience, vol. 14, no. 4, pp. 2260-2271, 1994.

[23] O. Suzuki, H. Hattori, M. Asano, M. Oya, and Y. Katsumata, "Inhibition of monoamine oxidase by $d$-methamphetamine," Biochemical Pharmacolgy, vol. 29, no. 14, pp. 2071-2073, 1980.

[24] F. Fornai, K. Chen, F. S. Giorgi, M. Gesi, M. G. Alessandri, and J. C. Shih, "Striatal dopamine metabolism in monoamine oxidase B-deficient mice: a brain dialysis study," Journal of Neurochemistry, vol. 73, no. 6, pp. 2434-2440, 1999.

[25] C. J. Schmidt and J. W. Gibb, "Role of the dopamine uptake carrier in the neurochemical response to methamphetamine: effects of amfonelic acid," European Journal of Pharmacology, vol. 109, no. 1, pp. 73-80, 1985.

[26] R. Moratalla, A. Khairnar, N. Simola et al., "Amphetaminerelated drugs neurotoxicity in humans and in experimental animals: main mechanisms," Progress in Neurobiology, vol. 155, pp. 149-170, 2017.

[27] J. L. Cadet, S. Ali, and C. Epstein, "Involvement of oxygenbased radicals in methamphetamine-induced neurotoxicity: 
evidence from the use of CuZnSOD transgenic mice," Annals of the New York Academy of Sciences, vol. 738, no. 1, pp. 388391, 2006.

[28] J. P. Spencer, M. Whiteman, P. Jenner, and B. Halliwell, "5-s-Cysteinyl-conjugates of catecholamines induce cell damage, extensive DNA base modification and increases in caspase-3 activity in neurons," Journal of Neurochemistry, vol. 81, no. 1, pp. 122-129, 2002.

[29] N. Granado, I. Lastres-Becker, S. Ares-Santos et al., "Nrf2 deficiency potentiates methamphetamine-induced dopaminergic axonal damage and gliosis in the striatum," Glia, vol. 59, no. 12, pp. 1850-1863, 2011.

[30] L. Mendieta, N. Granado, J. Aguilera, Y. Tizabi, and R. Moratalla, "Fragment $\mathrm{C}$ domain of tetanus toxin mitigates methamphetamine neurotoxicity and its motor consequences in mice," International Journal of Neuropsychopharmacology, vol. 19, no. 8, article pyw021, 2016.

[31] M. J. LaVoie and T. G. Hastings, "Dopamine quinone formation and protein modification associated with the striatal neurotoxicity of methamphetamine: evidence against a role for extracellular dopamine," The Journal of Neuroscience, vol. 19, no. 4, pp. 1484-1491, 1999.

[32] F. Fornai, P. Longone, M. Ferrucci et al., "Autophagy and amyotrophic lateral sclerosis: the multiple roles of lithium," Autophagy, vol. 4, no. 4, pp. 527-530, 2008.

[33] M. Ferrucci, L. Ryskalin, F. Biagioni et al., "Methamphetamine increases prion protein and induces dopaminedependent expression of protease resistant PrPsc," Archives Italiennes de Biologie, vol. 155, no. 1-2, pp. 8197, 2017.

[34] A. Moszczynska and B. K. Yamamoto, "Methamphetamine oxidatively damages parkin and decreases the activity of $26 \mathrm{~S}$ proteasome in vivo," Journal of Neurochemistry, vol. 116, no. 6, pp. 1005-1017, 2011.

[35] J. M. Brown, M. S. Quinton, and B. K. Yamamoto, "Methamphetamine-induced inhibition of mitochondrial complex II: roles of glutamate and peroxynitrite," Journal of Neurochemistry, vol. 95, no. 2, pp. 429-436, 2005.

[36] D. J. Barbosa, J. P. Capela, R. Feio-Azevedo, A. TeixeiraGomes, M. L. Bastos, and F. Carvalho, "Mitochondria: key players in the neurotoxic effects of amphetamines," Archives of Toxicology, vol. 89, no. 10, pp. 1695-1725, 2015.

[37] R. Castino, G. Lazzeri, P. Lenzi et al., "Suppression of autophagy precipitates neuronal cell death following low doses of methamphetamine," Journal of Neurochemistry, vol. 106, no. 3, pp. 1426-1439, 2008.

[38] G. Beauvais, K. Atwell, S. Jayanthi, B. Ladenheim, and J. L. Cadet, "Involvement of dopamine receptors in binge methamphetamine-induced activation of endoplasmic reticulum and mitochondrial stress pathways," PLoS One, vol. 6, no. 12, article e28946, 2011.

[39] P. Lenzi, R. Marongiu, A. Falleni et al., "A subcellular analysis of genetic modulation of PINK1 on mitochondrial alterations, autophagy and cell death," Archives Italiennes de Biologie, vol. 150, no. 2-3, pp. 194-217, 2012.

[40] B. K. Yamamoto and W. Zhu, "The effects of methamphetamine on the production of free radicals and oxidative stress," The Journal of Pharmacology and Experimental Therapy, vol. 287, no. 1, pp. 107-114, 1998.

[41] P. S. Fitzmaurice, J. Tong, M. Yazdanpanah, P. P. Liu, K. S. Kalasinsky, and S. J. Kish, "Levels of 4- hydroxynonenal and malondialdehyde are increased in brain of human chronic users of methamphetamine," The Journal of Pharmacology and Experimental Therapy, vol. 319, no. 2, pp. 703-709, 2006.

[42] F. Fornai, P. Lenzi, M. Gesi et al., "Fine structure and biochemical mechanisms underlying nigrostriatal inclusions and cell death after proteasome inhibition," Journal of Neuroscience, vol. 23, no. 26, pp. 8955-8966, 2003.

[43] G. Lazzeri, P. Lenzi, M. Gesi et al., "In PC12 cells neurotoxicity induced by methamphetamine is related to proteasome inhibition," Annals of the New York Academy of Sciences, vol. 1074, no. 1, pp. 174-177, 2006.

[44] K. E. Larsen, E. A. Fon, T. G. Hastings, R. H. Edwards, and D. Sulzer, "Methamphetamine-induced degeneration of dopaminergic neurons involves autophagy and upregulation of dopamine synthesis," Journal of Neurochemistry, vol. 22, no. 20, pp. 8951-8960, 2002.

[45] D. Weinshenker, M. Ferrucci, C. L. Busceti et al., "Genetic or pharmacological blockade of noradrenaline synthesis enhances the neurochemical, behavioral, and neurotoxic effects of methamphetamine," Journal of Neurochemistry, vol. 105, no. 2, pp. 471-483, 2008.

[46] X. L. Xie, J. T. He, Z. T. Wang et al., "Lactulose attenuates METH-induced neurotoxicity by alleviating the impaired autophagy, stabilizing the perturbed antioxidant system and suppressing apoptosis in rat striatum," Toxicology Letters, vol. 289, pp. 107-113, 2018.

[47] P. Lenzi, G. Lazzeri, F. Biagioni et al., "The autophagoproteasome a novel cell clearing organelle in baseline and stimulated conditions," Frontiers in Neuroanatomy, vol. 10, p. 78, 2016.

[48] D. J. Klionsky, K. Abdelmohsen, A. Abe et al., "Guidelines for the use and interpretation of assays for monitoring autophagy (3rd edition)," Autophagy, vol. 12, no. 1, pp. 1-222, 2016.

[49] F. Fornai, P. Lenzi, G. Lazzeri et al., "Fine ultrastructure and biochemistry of PC12 cells: a comparative approach to understand neurotoxicity," Brain Research, vol. 1129, no. 1, pp. 174-190, 2007.

[50] W. P. Melega, A. K. Cho, D. Harvey, and G. Laćan, "Methamphetamine blood concentrations in human abusers: application to pharmacokinetic modelling," Synapse, vol. 61, no. 4, pp. 216-220, 2007.

[51] Z. Wang, X. Shi, Y. Li et al., "Blocking autophagy enhanced cytotoxicity induced by recombinant human arginase in triple-negative breast cancer cells," Cell Death \& Disease, vol. 5, no. 12, article e1563, 2014

[52] Y. Chen, L. Hong, Y. Zeng, Y. Shen, and Q. Zeng, "Power frequency magnetic fields induced reactive oxygen speciesrelated autophagy in mouse embryonic fibroblasts," The International Journal of Biochemistry \& Cell Biology, vol. 57, pp. 108-114, 2014.

[53] A. Pla, M. Pascual, J. Renau-Piqueras, and C. Guerri, “TLR4 mediates the impairment of ubiquitin-proteasome and autophagy-lysosome pathways induced by ethanol treatment in brain," Cell Death \& Disease, vol. 5, no. 2, article e1066, 2014.

[54] K. Porter, J. Nallathambi, Y. Lin, and P. B. Liton, "Lysosomal basification and decreased autophagic flux in oxidatively stressed trabecular meshwork cells: implications for glaucoma pathogenesis," Autophagy, vol. 9, no. 4, pp. 581-594, 2013. 
[55] D. J. Klionsky and S. D. Emr, "Autophagy as a regulated pathway of cellular degradation," Science, vol. 290, no. 5497, pp. 1717-1721, 2000.

[56] A. Kuma, M. Hatano, M. Matsui et al., "The role of autophagy during the early neonatal starvation period," Nature, vol. 432, no. 7020, pp. 1032-1036, 2004.

[57] D. J. Klionsky, J. M. Cregg, W. A. Dunn Jr. et al., “A unified nomenclature for yeast autophagy-related genes," Developmental Cell, vol. 5, no. 4, pp. 539-545, 2003.

[58] G. J. Stout, E. C. Stigter, P. B. Essers et al., "Insulin/IGF-1mediated longevity is marked by reduced protein metabolism," Molecular Systems Biology, vo., vol. 9, no. 1, p. 679, 2013.

[59] D. Vilchez, I. Morantte, Z. Liu et al., "RPN-6 determines $C$. elegans longevity under proteotoxic stress conditions," Nature, vol. 489, no. 7415, pp. 263-268, 2012.

[60] K. B. Hendil, P. Kristensen, and W. Uerkvitz, "Human proteasomes analysed with monoclonal antibodies," Biochemical Journal, vol. 305, no. 1, pp. 245-252, 1995.

[61] M. Kovarik, T. Muthny, L. Sispera, and M. Holecek, "Effects of $\beta$-hydroxy- $\beta$-methylbutyrate treatment in different types of skeletal muscle of intact and septic rats," Journal of Physiology and Biochemistry, vol. 66, no. 4, pp. 311-319, 2010.

[62] E. Jo, J. McLaurin, C. M. Yip, P. St. George-Hyslop, and P. E. Fraser, " $\alpha$-Synuclein membrane interactions and lipid specificity," Journal of Biological Chemistry, vol. 275, no. 44, pp. 34328-34334, 2000.

[63] Y. Liu, L. Fallon, H. A. Lashuel, Z. Liu, and P. T. Lansbury Jr, "The UCH-L1 gene encodes two opposing enzymatic activities that affect alpha-synuclein degradation and Parkinson's disease susceptibility," Cell, vol. 111, no. 2, pp. 209-218, 2002.

[64] L. Maroteaux, J. T. Campanelli, and R. H. Scheller, "Synuclein: a neuron-specific protein localized to the nucleus and presynaptic nerve terminal," Journal of Neuroscience, vol. 8, no. 8, pp. 2804-2815, 1988.

[65] N. Ostrerova-Golts, L. Petrucelli, J. Hardy, J. M. Lee, M. Farer, and B. Wolozin, "The A53T alpha-synuclein mutation increases iron-dependent aggregation and toxicity," Journal of Neuroscience, vol. 20, no. 16, pp. 6048-6054, 2000.

[66] H. van der Putten, K. H. Wiederhold, A. Probst et al., "Neuropathology in mice expressing human alpha-synuclein," Journal of Neuroscience, vol. 20, no. 16, pp. 6021-6029, 2000.

[67] F. Bartolome, M. de la Cueva, C. Pascual et al., "Amyloid $\beta$-induced impairments on mitochondrial dynamics, hippocampal neurogenesis, and memory are restored by phosphodiesterase 7 inhibition," Alzheimer's Research and Therapy, vol. 10, no. 1, p. 24, 2018.

[68] R. Flores-Costa, J. Alcaraz-Quiles, E. Titos et al., “The soluble guanylate cyclase stimulator IW-1973 prevents inflammation and fibrosis in experimental non-alcoholic steatohepatitis," British Journal of Pharmacology, vol. 175, no. 6, pp. 953967, 2018.

[69] P. Wang, L. Jiang, N. Zhou et al., "Resveratrol ameliorates autophagic flux to promote functional recovery in rats after spinal cord injury," Oncotarget, vol. 9, no. 9, pp. 8427-8440, 2018.

[70] D. Sun, W. Wang, X. Wang et al., "bFGF plays a neuroprotective role by suppressing excessive autophagy and apoptosis after transient global cerebral ischemia in rats," Cell Death \& Disease, vol. 9, no. 2, p. 172, 2018.
[71] A. Du, S. Huang, X. Zhao et al., "Suppression of CHRN endocytosis by carbonic anhydrase CAR3 in the pathogenesis of myasthenia gravis," Autophagy, vol. 13, no. 11, pp. 19811994, 2017.

[72] N. Pullen and G. Thomas, "The modular phosphorylation and activation of p70s6k," FEBS Letters, vol. 410, no. 1, pp. 78-82, 1997.

[73] D. R. Alessi, M. T. Kozlowski, Q. P. Weng, N. Morrice, and J. Avruch, "3-Phosphoinositide-dependent protein kinase 1 (PDK1) phosphorylates and activates the p70 S6 kinase in vivo and in vitro," Current Biology, vol. 8, no. 2, pp. 6981, 1998.

[74] R. D. Polakiewicz, S. M. Schieferl, A. C. Gingras, N. Sonenberg, and M. J. Comb, " $\mu$-Opioid receptor activates signaling pathways implicated in cell survival and translational control," Journal of Biological Chemistry, vol. 273, no. 36, pp. 23534-23541, 1998.

[75] D. C. Finger, S. Salama, C. Tsou, E. Harlow, and J. Blenis, "Mammalian cell size is controlled by mTOR and its downstream targets S6K1 and 4EBP1/eIF4E," Genes \& Development, vol. 16, no. 12, pp. 1472-1487, 2002.

[76] M. Saitoh, N. Pullen, P. Brennan, D. Cantrell, P. B. Dennis, and G. Thomas, "Regulation of an activated S6 kinase 1 variant reveals a novel mammalian target of rapamycin phosphorylation site," Journal of Biological Chemistry, vol. 277, no. 22, pp. 20104-20112, 2002.

[77] M. Bendayan and M. Zollinger, "Ultrastructural localization of antigenic sites on osmium-fixed tissues applying the protein A-gold technique," The Journal of Histochemistry \& Cytochemistry, vol. 31, no. 1, pp. 101-109, 1983.

[78] D. D'Alessandro, L. Mattii, S. Moscato et al., "Immunohistochemical demonstration of the small GTPase RhoAA on epoxy-resin embedded sections," Micron, vol. 35, no. 4, pp. 287-296, 2004.

[79] J. M. Lucocq, A. Habermann, S. Watt, J. M. Backer, T. M. Mayhew, and G. Griffiths, "A rapid method for assessing the distribution of gold labeling on thin sections," Journal of Histochemistry \& Cytochemistry, vol. 52, no. 8, pp. 9911000, 2004.

[80] J. Ma, J. Wan, J. Meng, S. Banerjee, S. Ramakrishnan, and S. Roy, "Methamphetamine induces autophagy as a prosurvival response against apoptotic endothelial cell death through the Kappa opioid receptor," Cell Death \& Disease, vol. 5, no. 3, article e1099, 2014.

[81] G. V. Rinetti and F. E. Schweizer, "Ubiquitination acutely regulates presynaptic neurotransmitter release in mammalian neurons," Journal of Neuroscience, vol. 30, no. 9, pp. 31573166, 2010.

[82] C. Wentzel, I. Delvendahl, S. Sydlik, O. Georgiev, and M. Müller, "Dysbindin links presynaptic proteasome function to homeostatic recruitment of low release probability vesicles," Nature Communications, vol. 9, no. 1, p. 267, 2018.

[83] J. Konieczny, T. Lenda, and A. Czarnecka, "Early increase in dopamine release in the ipsilateral striatum after unilateral intranigral administration of lactacystin produces spontaneous contralateral rotations in rats," Neuroscience, vol. 324, pp. 92-106, 2016.

[84] P. Barroso-Chinea, M. L. Thiolat, S. Bido et al., "D1 dopamine receptor stimulation impairs striatal proteasome activity in parkinsonism through $26 \mathrm{~S}$ proteasome disassembly," Neurobiology of Disease, vol. 78, pp. 77-87, 2015. 
[85] N. Ueda, T. Tomita, K. Yanagisawa, and N. Kimura, "Retromer and Rab2-dependent trafficking mediate PS1 degradation by proteasomes in endocytic disturbance," Journal of Neurochemistry, vol. 137, no. 4, pp. 647-658, 2016.

[86] V. Cohen-Kaplan, A. Ciechanover, and I. Livneh, "p62 at the crossroad of the ubiquitin-proteasome system and autophagy,” Oncotarget, vol. 7, no. 51, pp. 83833-83834, 2016.

[87] S. Engelender, " $\alpha$-Synuclein fate: proteasome or autophagy?," Autophagy, vol. 8, no. 3, pp. 418-420, 2012.

[88] M. Xilouri, O. R. Brekk, and L. Stefanis, " $\alpha$-Synuclein and protein degradation systems: a reciprocal relationship," Molecular Neurobiology, vol. 47, no. 2, pp. 537-551, 2013.

[89] J. L. Webb, B. Ravikumar, J. Atkins, J. N. Skepper, and D. C. Rubinsztein, "Alpha-synuclein is degraded by both autophagy and the proteasome," Journal of Biological Chemistry, vol. 278, no. 27, pp. 25009-25013, 2003.

[90] M. Ferrucci, L. Pasquali, S. Ruggieri, A. Paparelli, and F. Fornai, "Alpha-synuclein and autophagy as common steps in neurodegeneration," Parkinsonism \& Related Disorders, vol. 14, Supplement 2, pp. S180-S184, 2008.

[91] F. Yang, Y. P. Yang, C. J. Mao et al., "Crosstalk between the proteasome system and autophagy in the clearance of $\alpha$ synuclein," Acta Pharmacologica Sinica, vol. 34, no. 5, pp. 674-680, 2013.

[92] A. S. Krall, S. Xu, T. G. Graeber, D. Braas, and H. R. Christofk, "Asparagine promotes cancer cell proliferation through use as an amino acid exchange factor," Nature Communications, vol. 7, article 11457, 2016.

[93] R. Loewith, E. Jacinto, S. Wullschleger et al., "Two TOR complexes, only one of which is rapamycin sensitive, have distinct roles in cell growth control," Molecular Cell, vol. 10, no. 3, article 10.1016/s1097-2765(02)00636-6, pp. 457-468, 2002.

[94] Y. Li, Z. Hu, B. Chen et al., "Taurine attenuates methamphetamine-induced autophagy and apoptosis in PC12 cells through mTOR signaling pathway," Toxicology Letters, vol. 215, no. 1, pp. 1-7, 2012.

[95] J. Wu, D. Zhu, J. Zhang, G. Li, Z. Liu, and J. Sun, "Lithium protects against methamphetamine-induced neurotoxicity in PC12 cells via Akt/GSK3 $\beta /$ mTOR pathway," Biochemical and Biophysical Research Communication, vol. 465, no. 3, pp. 368-373, 2015.

[96] P. Kongsuphol, S. Mukda, C. Nopparat, A. Villarroel, and P. Govitrapong, "Melatonin attenuates methamphetamineinduced deactivation of the mammalian target of rapamycin signaling to induce autophagy in SK-N-SH cells," Journal of Pineal Research, vol. 46, no. 2, pp. 199-206, 2008.

[97] S. H. Huang, W. R. Wu, L. M. Lee, P. R. Huang, and J. C. Chen, "mTOR signaling in the nucleus accumbens mediates behavioral sensitization to methamphetamine," Progress in Neuro-Psychopharmacology \& Biological Psychiatry, vol. 86, pp. 331-339, 2018.

[98] F. Fornai, P. Lenzi, L. Capobianco et al., "Involvement of dopamine receptors and beta-arrestin in metamphetamineinduced inclusions formation in PC12 cells," Journal of Neurochemistry, vol. 105, no. 5, pp. 1939-1947, 2008.

[99] D. Wang, X. Ji, J. Liu, Z. Li, and X. Zhang, "Dopamine receptor subtypes differentially regulate autophagy," International Journal of Molecular Sciences, vol. 19, no. 5, p. 1540, 2018.

[100] R. Pitaksalee, Y. Sanvarida, T. Sinchai et al., "Autophagy inhibition by caffeine increases toxicity of methamphetamine in
SH-SY5Y neuroblastoma cell line," Neurotoxicity Research, vol. 27, no. 4, pp. 421-429, 2015.

[101] L. Cao, M. Fu, S. Kumar, and A. Kumar, "Methamphetamine potentiates HIV-1 gp120-mediated autophagy via Beclin-1 and Atg5/7 as a pro-survival response in astrocytes," Cell Death \& Disease, vol. 7, no. 10, article e2425, 2016.

[102] C. Zhao, Y. Mei, X. Chen et al., “Autophagy plays a prosurvival role against methamphetamine-induced apoptosis in H9C2 cells," Toxicology Letters, vol. 294, pp. 156-165, 2018.

[103] S. Chandra, G. Gallardo, R. Fernández-Chacón, O. M. Schlüter, and T. C. Südhof, " $\alpha$-synuclein cooperates with $\operatorname{CSP} \alpha$ in preventing neurodegeneration," Cell, vol. 123, no. 3, pp. 383-396, 2005.

[104] Y. Machida, T. Chiba, A. Takayanagi et al., "Common antiapoptotic roles of parkin and $\alpha$-synuclein in human dopaminergic cells," Biochemical and Biophysical Research Communications, vol. 332, no. 1, pp. 233-240, 2005.

[105] O. M. Schlüter, F. Fornai, M. G. Alessandrí et al., "Role of alpha-synuclein in 1-methyl-4-phenyl-1,2,3,6-tetrahydropyridine-induced parkinsonism in mice," Neuroscience, vol. 118, no. 4, pp. 985-1002, 2003.

[106] W. H. Song, Y. J. Yia, M. Sutovskya, S. Meyers, and P. Sutovsky, "Autophagy and ubiquitin-proteasome system contribute to sperm mitophagy after mammalian fertilization," Proceedings of the National Academy of Sciences of the United States of America, vol. 113, no. 36, pp. E5261-E5270, 2016.

[107] S. Akabane, K. Matsuzaki, S. Yamashita et al., "Constitutive activation of PINK1 protein leads to proteasome-mediated and non-apoptotic cell death independently of mitochondrial autophagy," The Journal of Biological Chemistry, vol. 291, no. 31, pp. 16162-16174, 2016. 


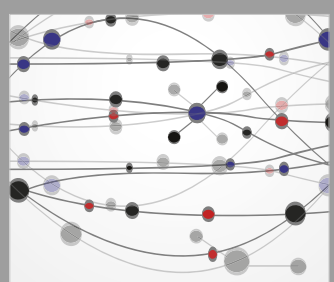

The Scientific World Journal
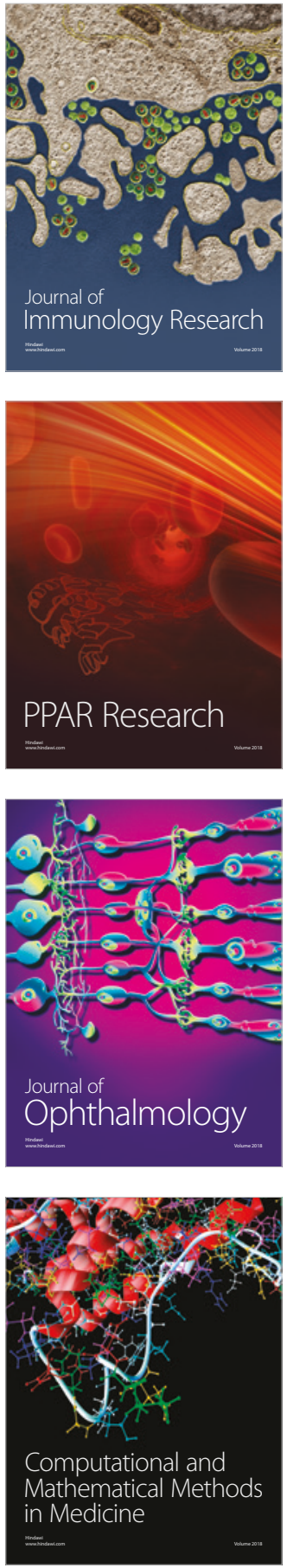

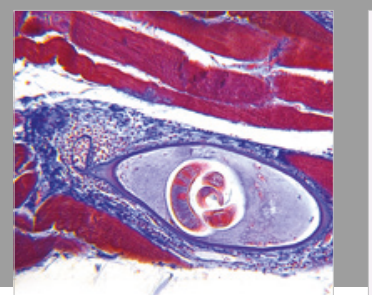

Gastroenterology Research and Practice

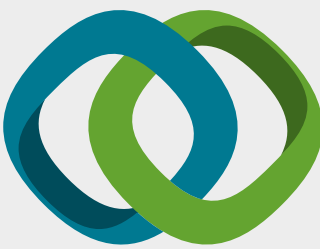

\section{Hindawi}

Submit your manuscripts at

www.hindawi.com
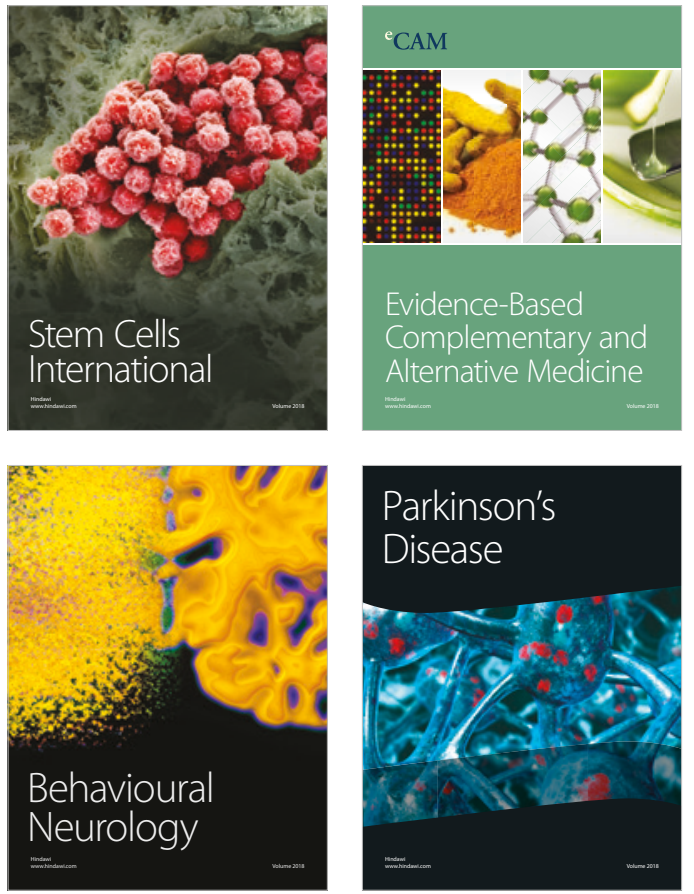

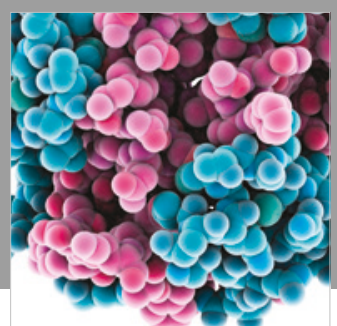

ournal of

Diabetes Research

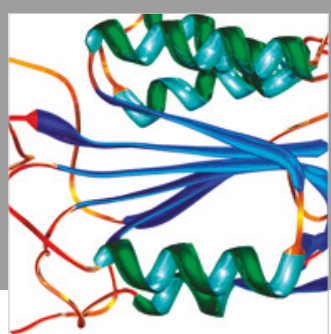

Disease Markers
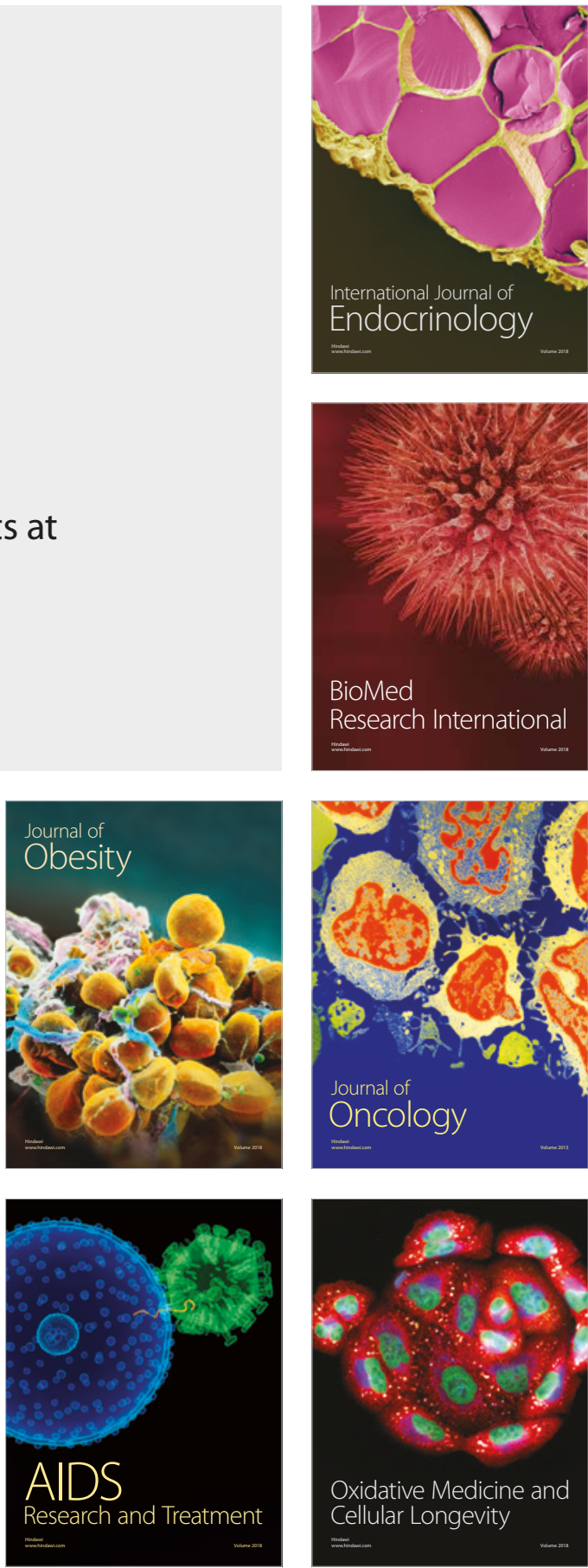